\title{
Developmental regulation of ecdysone receptor $(E c R)$ and EcR-controlled gene expression during pharate-adult development of honeybees (Apis mellifera)
}

\author{
Tathyana R. P. Mello ${ }^{1}$, Aline C. Aleixo ${ }^{1}$, Daniel G. Pinheiro ${ }^{2}$, Francis M. F. Nunes ${ }^{3}$, \\ Márcia M. G. Bitondi ${ }^{4}$, Klaus Hartfelder ${ }^{5}$, Angel R. Barchuk ${ }^{6 *}$ and Zilá L. P. Simões ${ }^{4}$
}

\footnotetext{
${ }^{1}$ Departamento de Genética, Faculdade de Medicina de Ribeirão Preto, Universidade de São Paulo, São Paulo, Brazil

${ }^{2}$ Faculdade de Ciências Agrárias e Veterinárias, Universidade Estadual Paulista, São Paulo, Brazil

${ }^{3}$ Departamento de Genética e Evolução, Centro de Ciências Biológicas e da Saúde, Universidade Federal de São Carlos, São Carlos, Brazil

${ }^{4}$ Departamento de Biologia, Faculdade de Filosofia, Ciências e Letras de Ribeirão Preto, Universidade de São Paulo, São Paulo, Brazil

${ }^{5}$ Departamento de Biologia Celular, Molecular e de Bioagentes Patogênicos, Faculdade de Medicina de Ribeirão Preto, Universidade de São Paulo, São Paulo, Brazil

${ }^{6}$ Laboratório de Biologia Animal Integrativa, Departamento de Biologia Celular, Tecidual e do Desenvolvimento, Instituto de Ciências Biomédicas, Universidade Federal de Alfenas, Alfenas, Brazil
}

\section{Edited by:}

Greg J. Hunt, Purdue University, USA

\section{Reviewed by:}

Xavier Belles, Institute of

Evolutionary Biology (CSIC-UPF),

Spain

Joanna Kelley, Stanford University, USA

\section{*Correspondence:}

Angel R. Barchuk, Departamento de

Biologia Celular, Tecidual e do

Desenvolvimento, Instituto de Ciências Biomédicas, Universidade Federal de Alfenas, Rua Gabriel Monteiro Silva, 700, CEP 37130-000

Campus Sede, Alfenas, Brazil e-mail: barchuk@unifal-mg.edu.br; arbarchuk@yahoo.com
Major developmental transitions in multicellular organisms are driven by steroid hormones. In insects, these, together with juvenile hormone (JH), control development, metamorphosis, reproduction and aging, and are also suggested to play an important role in caste differentiation of social insects. Here, we aimed to determine how $E C R$ transcription and ecdysteroid titers are related during honeybee postembryonic development and what may actually be the role of EcR in caste development of this social insect. In addition, we expected that knocking-down EcR gene expression would give us information on the participation of the respective protein in regulating downstream targets of EcR. We found that in Apis mellifera females, EcR-A is the predominantly expressed variant in postembryonic development, while EcR-B transcript levels are higher in embryos, indicating an early developmental switch in EcR function. During larval and pupal stages, EcR-B expression levels are very low, while EcR-A transcripts are more variable and abundant in workers compared to queens. Strikingly, these transcript levels are opposite to the ecdysteroid titer profile. 20-hydroxyecdysone (20E) application experiments revealed that low $20 \mathrm{E}$ levels induce ECR expression during development, whereas high ecdysteroid titers seem to be repressive. By means of RNAi-mediated knockdown (KD) of both EcR transcript variants we detected the differential expression of 234 poly-A $\mathrm{A}^{+}$transcripts encoding genes such as CYPs, MRJPs and certain hormone response genes (Kr-h1 and ftz-f1). EcR-KD also promoted the differential expression of 70 miRNAs, including highly conserved ones (e.g., miR-133 and miR-375), as well honeybee-specific ones (e.g., miR-3745 and miR-3761). Our results put in evidence a broad spectrum of EcR-controlled gene expression during postembryonic development of honeybees, revealing new facets of EcR biology in this social insect.

Keywords: honey bee, adult development, 20E, ecdysteroid, juvenile hormone, JH, RNAi, miRNA

\section{INTRODUCTION}

Most multicellular organisms go through developmental transitions that enable them to cope with environmental changes and/or broaden their niche possibilities. Such transitions are generally timed and synchronized by morphogenetic hormones in a broad range of species, including insects, amphibians, metamorphic fish, tunicates, echinoderms, and plants. In insects, developmental transitions, such as larval and metamorphic molts, are driven by steroid hormones (ecdysteroids) acting in conjunction with juvenile hormone $(\mathrm{JH})$. These hormones also control reproduction and aging (Flatt et al., 2005; Gáliková et al., 2011), and, in social insects, play important roles in caste polyphenism (Hartfelder and Emlen, 2012).

The steroid hormone ecdysone is produced by the prothoracic glands. After secretion, it is transported via the hemolymph to its target organs. Due to its lipophilic nature it passes directly into the cytoplasm of target and/or modification center cells (Iga and Kataoka, 2012; Ono, 2014), where it can be modified to 20-hydroxyecdysone (20E) by a 20-monooxygenase encoded by the shade gene, a member of the cytochrome P450 family (CYP314a1) known as Halloween (Petryk et al., 2003). The mode of action of $\mathrm{JH}$, which is a sesquiterpenoid morphogenetic molecule, has only recently become clear (for review see 
Bellés and Santos, 2014), both in terms of its receptor and downstream cascade, as well as its molecular interaction with ecdysteroids. Produced by the corpora allata in the retrocerebral complex, $\mathrm{JH}$ relies on binding proteins for its transport in the hemolymph to target cells. There, it first binds to its intracellular receptor, the Methoprenetolerant (Met) protein, which then forms a complex with Taiman (Charles et al., 2011). This dimeric hormonereceptor complex then regulates the expression of target genes.

Knowledge on the mechanism of action of insect ecdysteroids initiated with the early work of Clever and Carlson (for a historical review see Bellés and Santos, 2014), which eventually resulted in the so-called Ashburner model (Ashburner et al., 1974), which proposed a general model for the action of ecdysone, based on its participation in the regulation of gene expression (puffing) in the polytenic salivary gland chromosomes during Drosophila melanogaster molting and metamorphosis. Briefly, the model states that ecdysone associates with an intracellular receptor protein to activate early genes encoding transcription factors, which then activate late genes and, on the other, inhibit the transcription of previously activated early genes. The receptor protein and certain other members of this cascade belong to a large family of proteins, the nuclear hormone receptors (NR, see Fahrbach et al., 2012). NR proteins are generally comprised of four independent but functionally interacting domains. A/B is a highly variable domain that may contain a motif (AF-1) driving ligand-independent transcription. The second, the $\mathrm{C}$ domain, is a DNA-binding domain (DBD), the most conserved region of NRs. The D or hinge domain provides a link between DBD and the next domain, LBD, a multifunctional domain that mediates ligand binding, dimerization, and interaction with heat shock proteins, nuclear localization, and transactivation functions. Functional NRs form homodimers and/or heterodimers that recognize specific DNA sequences. In the absence of a ligand molecule they act as repressors maintaining target genes inhibited by co-repressor complexes. In the presence of hormone they are activators of target genes by recruiting co-activator proteins and displacing corepressors (Hill et al., 2013; Yamanaka et al., 2013; Evans and Mangelsdorf, 2014).

The functional ecdysone receptor is a heterodimeric NR formed by the Ecdysone Receptor (EcR) and the ultraspiracle (usp) gene products (for a comprehensive review, see Hill et al., 2013). USP is an ortholog of the vertebrate retinoid-X receptor (RXR) (Yao et al., 1992) and is most commonly considered a kind of orphan NR. Though its ligand is not known, its participation as a mediator of $\mathrm{JH}$ action has been postulated, probably through a direct binding of JH (Barchuk et al., 2004). Furthermore, the EcR/USP complex can also bind to the let-7- $C$ gene after a $20 \mathrm{E}$ pulse has triggered the larval-to-pupal metamorphic molt, thus inducing the transcription of a cluster of three microRNAs (miR-100, let-7 and miR-125). These then post-transcriptionally regulate the expression of genes involved in neuromuscular morphogenesis, leading to adult body characteristics (Chawla and Sokol, 2012; see also Rubio and Bellés, 2013). The EcR protein can also per se regulate the expression of target genes (Davis and Li, 2013), thus adding extra levels of complexity to the mechanisms and gene regulatory networks involving hormone/transcription factor activities.

In insects showing caste polyphenism, there is evidence that ecdysteroids are important players in caste differentiation, not only during post embryonic, but possibly even during embryonic development (Schwander et al., 2008). The role of ecdysteroids in caste development and regulation of adult reproduction is currently best understood in bees, especially so in the bumblebee Bombus terrestris (Geva et al., 2005) and in the honeybee Apis mellifera (Hartfelder and Engels, 1998), where they participate in the regulation of the differential morphogenesis programs by interacting with $\mathrm{JH}$ and possibly other mediating environmental modulators.

Receptor proteins mediating ecdysteroids action in social insects have been studied mainly in the honeybee (The Honey Bee Genome Sequencing Consortium, 2006; Velarde et al., 2006), where USP and EcR cDNAs have been cloned (Barchuk et al., 2004; Takeuchi et al., 2007), and the expression profiles of the respective genes were determined in several organs, tissues, and conditions (Barchuk et al., 2004, 2008; Takeuchi et al., 2007; Velarde et al., 2009). However, and despite all these works, several responses to differential hormone signaling in honeybee caste development are still poorly understood (Barchuk et al., 2007). For instance, ecdysteroid titers in developing females are higher in queens during the second half of the last larval instar (Rachinsky et al., 1990) and differ in their profiles during pupal and pharateadult development of queens and workers (Pinto et al., 2002). These hormone titer differences are associated with the differential development of specific structures (e.g., brain and ovary, Barchuk et al., 2007) and also the onset of vitellogenin synthesis (Barchuk et al., 2002), but this is essentially correlative information lacking functional support. Herein we aimed at determining the extent to which $E c R$ transcription follows ecdysteroids titers during honeybee postembryonic development and can actually mediate the action of molecular determinants of caste development in honeybees. Moreover, we expected that knocking-down $E c R$ gene expression during pharate-adult development would bring to light new downstream targets of EcR.

\section{MATERIALS AND METHODS \\ BEES}

Embryos and the successive developmental phases in the larval and pupal stages, as well as newly-emerged adults were obtained from A. mellifera colonies (Africanized hybrids) maintained at the Experimental Apiary of the University of São Paulo at Ribeirão Preto, Brazil. The developmental phases of workers and queens (Table 1) were identified according to Rembold (1987) and Michelette and Soares (1993). Immediately after sampling, the bees were immersed in TRIzol reagent (Life Technologies) and frozen at $-80^{\circ} \mathrm{C}$ until RNA extraction.

\section{NORTHERN BLOT ANALYSIS}

Approximately $15 \mu \mathrm{g}$ of total RNA extracted from queens and workers at the PP1 and Pb developmental stages were subjected to electrophoresis in a denaturing $1.5 \%$ agarose/formaldehyde gel, and the RNA was then transferred to a PVF (Polyvinylidene Fluoride, GE) membrane using a VacuGene XL Vacuum Blotting 
Table 1 | Developmental stages (embryonic, larval, pupal, adult) of A. mellifera considered in this work.

\begin{tabular}{|c|c|}
\hline Abbreviation & Developmental stage \\
\hline$E$ & Embryo \\
\hline L1 & First instar larva \\
\hline L2 & Second instar larva \\
\hline L3 & Third instar larva \\
\hline L4 & Fourth instar larva \\
\hline L5F1 & Fifth instar larva, feeding phase 1 \\
\hline L5F2 & Fifth instar larva, feeding phase 2 \\
\hline L5F3 & Fifth instar larva, feeding phase 3 \\
\hline L5S1 & Fifth instar larva, cocoon-spinning phase 1 \\
\hline L5S2 & Fifth instar larva, cocoon-spinning phase 2 \\
\hline L5S3 & Fifth instar larva, cocoon-spinning phase 3 \\
\hline PP1 & Fifth instar larva, prepupa 1 \\
\hline PP2 & Fifth instar larva, prepupa 2 \\
\hline PP3 & Fifth instar larva, prepupa 3 \\
\hline Pw & White-eyed pupa, unpigmented cuticle \\
\hline $\mathrm{Pp}$ & Pink-eyed/pharate-adult transition, unpigmented cuticle \\
\hline Pdp & Dark pink-eyed pharate-adult, unpigmented cuticle \\
\hline $\mathrm{Pb}$ & Brown-eyed pharate-adult, unpigmented cuticle \\
\hline $\mathrm{Pbl}$ & Brown-eyed pharate-adult, light pigmented cuticle \\
\hline $\mathrm{Pbm}$ & Brown-eyed pharate-adult, intermediary pigmented cuticle \\
\hline Pbd & Brown-eyed pharate-adult, dark pigmented cuticle \\
\hline NE & Newly emerged adult \\
\hline
\end{tabular}

system (GE Healthcare). An EcR cDNA fragment of $160 \mathrm{bp}$ encoding the $3^{\prime}$ part of the DNA-binding domain was used for probe synthesis by means of the Random Primers DNA Labeling System (Life Technologies) and Redivue ${ }^{32} \mathrm{P}$-nucleotides (Amersham). After $3 \mathrm{~h}$ of hybridization at $42^{\circ} \mathrm{C}$, the membranes were washed during $20 \mathrm{~min}$ with $0.1 \times$ SSC solution containing $0.1 \%$ SDS and then exposed to a Super Sensitive ST film and the bands revealed with Cyclone ${ }^{\mathrm{TM}}$ Storage Phosphor System (PerkinElmer).

\section{HORMONE TREATMENTS}

For the analysis of the $E c R$ expression response to artificially augmented levels of hormones, workers at the brown-eyed pupal phase $(\mathrm{Pb})$ were removed from the brood frames and maintained in an incubator at $34^{\circ} \mathrm{C}$ and $80 \%$ relative humidity. For the ecdysone response, three groups of 3-7 workers were injected with $5 \mu \mathrm{g}$ of 20-hydroxyecdysone (20E; Sigma) dissolved in $2 \mu \mathrm{L}$ Ringer saline containing $12.5 \%$ ethanol. For the $\mathrm{JH}$ response, a similar number of $\mathrm{Pb}$-phase workers received a topical application of $10 \mu \mathrm{g} \mathrm{JH}$-III (Fluka) dissolved in $2 \mu \mathrm{L}$ acetone. Controls received $2 \mu \mathrm{L}$ of the respective solvents. The amounts of applied hormone were based on previous experiments in which we had examined their effects on inducing gene expression during pupal stage (Barchuk et al., 2002, 2004). RNA was isolated from fat bodies after 1, 12, and $24 \mathrm{~h}$ (independent experiments). Fat bodies were obtained via a longitudinal incision in isolated abdomens, which were then kept under gentle agitation in Petri dishes containing $0.9 \% \mathrm{NaCl}$. The resultant suspension of dispersed fat body cells was centrifuged during $1 \mathrm{~min}$ at $2500 \times \mathrm{g}$ and the pellet was transferred into TRIzol reagent and frozen at $-80^{\circ} \mathrm{C}$ until RNA extraction. We used fat bodies because this allowed us to specifically assay this metabolically important organ, especially with regard to vitellogenin $(v g)$ gene expression in honeybees.

\section{RNA EXTRACTION, REVERSE TRANSCRIPTION AND OUANTITATIVE PCR ASSAYS}

Total RNA was isolated using TRIzol (Life Technologies), following the manufacturer's protocol, and purified by column purification (RNeasy Mini Kit, QIAGEN), as described previously (Barchuk et al., 2004, 2007). For the quantification of mRNA levels (except those validating the RNA-Seq data), first strand cDNA was synthesized by reverse transcription from $2 \mu \mathrm{g}$ of RNA with SuperScript II Reverse Transcriptase (Life Technologies) and an oligo(dT) ${ }_{12-18}$ primer (Life Technologies). For the validation of the RNA-Seq libraries, cDNA was synthesized using $\mathrm{NCode}^{\mathrm{TM}}$ miRNA First-Strand cDNA Synthesis and qRT-PCR (Invitrogen) kits and their instructions, adding a DNase (Promega) treatment step.

Comparative analyses of transcript levels were performed by Real Time quantitative PCR (qPCR) using a 7500 Real-Time PCR System (Applied Biosystems) or a StepOne Plus system (Applied Biosystems). Amplifications were carried out in $20 \mu \mathrm{L}$ reaction mixtures, each containing $10 \mu \mathrm{L}$ of $\mathrm{SYBR}^{\circledR}$ Green Master Mix $2 \times$ (Applied Biosystems), $0.8 \mu \mathrm{L}$ of a $10 \mathrm{mM}$ stock solution of each of the gene-specific forward and reverse primers (Table $\mathrm{S} 1$ ), and $1 \mu \mathrm{L}$ of first-strand cDNA diluted 1:4 (or 1:10, for cDNA samples used to validate RNA-Seq data) in ultrapure water. The sequences of forward primers were identical to the mature miRNA sequences available at miRBase, but replacing $U$ by $T$, while the reverse Universal qPCR primer is supplied by NCode kit. Reaction conditions were $50^{\circ} \mathrm{C}$ for $2 \mathrm{~min}, 95^{\circ} \mathrm{C}$ for $10 \mathrm{~min}$, followed by 40 cycles of $95^{\circ} \mathrm{C}$ for $15 \mathrm{~s}$ and $60^{\circ} \mathrm{C}$ for $1 \mathrm{~min}$ (or $33 \mathrm{~s}$ for miRNA amplification). Three biological replicates were run in three technical replicates each. Actin related protein 1 (Arp1, GenBank accession number NM_001185145.1), rpl32 (accession number NM_001011587.1), or a U5 snRNA gene were used as reference genes (for confirmation, cDNAs for all three reference genes were partially sub-cloned and sequenced in our laboratory). Relative quantities of transcripts were calculated using the comparative Ct method (Applied Biosystems, User bulletin\#2). Statistical analyses were carried out with Statistica version 7.0 (http://statistica.software.informer.com/).

\section{ASSESSING GENE TRANSCRIPTION PATTERNS ASSOCIATED TO ECR FUNCTION DURING HONEYBEE DEVELOPMENT USING RNAi dsRNA synthesis and treatment}

We employed a general protocol for dsRNA synthesis and injection in honeybees (Pbl phase) (Amdam et al., 2003). For $E c R$ dsRNA synthesis, a 391 bp clone of EcR cDNA was amplified to serve as template, this comprising a fragment shared by the two transcript variants (A and $\mathrm{B}$ ). The primers with the respective recognition site for T7 RNA polymerase (underlined) were: $E c R$-forward 5'-TAATACGACTCACTATAGGGCGAGAAT GGCGAGGAAGTACGAC and EcR-reverse 5'-TAATACGACT CACTATAGGGCGATTCTTGAACTTGAGGCTGAAG. A green fluorescent protein (GFP) gene clone was used as template to 
synthesize the respective dsRNA used as a non-target control (GFP-forward 5'-TAATACGACTCACTATAGGGCGAAGTGGA GAGGGTGAAGGTGA-3 $3^{\prime}$ and GFP-reverse $5^{\prime}$-TAATACGACTC ACTATAGGGCGAGGTAAAAGGACAGGGCCATC- ${ }^{\prime}$; see Nunes et al., 2013a). The amplification products were visualized and retrieved after agarose gel electrophoresis and purified using QIAquick $^{\mathrm{TM}}$ (QIAGEN) columns. In vitro transcription reactions were performed by using the RiboMax ${ }^{\mathrm{TM}} \mathrm{T} 7$ system (Promega) and the obtained dsRNA was isolated using TRIzol LS reagent (Invitrogen), subjected to a denaturation step at $98^{\circ} \mathrm{C}$ for $5 \mathrm{~min}$, followed by $30 \mathrm{~min}$ at room temperature, and diluted with nuclease free water to a final concentration of $2.5 \mu \mathrm{g} / \mu \mathrm{L}$. The dsRNA quality was assessed by agarose gel electrophoresis.

Pbl-phase workers ( $n=30$ for each experimental group) received an intra-abdominal injection of $2 \mu \mathrm{L}$ of $E c R$ dsRNA solution $(2.5 \mu \mathrm{g} / \mu \mathrm{L})$. Controls of the same developmental phase received the same volume of GFP dsRNA solution. dsRNAinjected bees were kept in an incubator at $34^{\circ} \mathrm{C}$ and $80 \%$ relative humidity until adult eclosion $(\sim 2$ days), when they were transferred to TRIzol reagent (Invitrogen) and frozen at $-80^{\circ} \mathrm{C}$ until RNA extraction. Total RNA extraction and first strand cDNA synthesis were carried out as described above. EcR knockdown efficiencies were assessed by RT-qPCR using variant-specific primers (EcRA-F, EcRB-F, and EcRA/B-R; see Table S1). Bees not used for gene expression analysis were used for evaluation of the adult phenotype.

\section{Analysis of gene expression patterns by RNA-Seq}

RNA pools of equal concentration from each group of EcRand GFP-dsRNA treated bees were used for RNA-sequencing. Libraries were prepared using the TruSeq RNA ${ }^{\mathrm{TM}}$ Sample Preparation kit (Illumina) for poly-A ${ }^{+}$RNA, and the TruSeq ${ }^{\mathrm{TM}}$ Small RNA Sample preparation kit (Illumina) for small RNAs (shorter than $200 \mathrm{nt}$ ). These libraries were shipped to the University of North Carolina (Chapel Hill, USA) facility where they were sequenced on an Illumina platform (Genome Analyzer II, Life Sciences).

RNA-Seq reads for the poly-A ${ }^{+}$RNA library were first submitted to adapter clipping using Scythe (Buffalo, 2011) (v.0.981default parameters) for the $3^{\prime}$-end adapter and CutAdapt (Martin, 2011) (v.1.1 - minimum overlap of $5 \mathrm{bp}$ ) for the $5^{\prime}$-end adapter. The next step was read trimming based on quality scores (mean $Q \geq 25$ ), Ns (number of $N$ bases lower than 10\%) and poly-A tail prediction (minimum of $5 \mathrm{bp}$ of $\mathrm{A} / \mathrm{T}$ at both ends). This step was performed using PRINSEQ (v.0.19.5) (Schmieder and Edwards, 2011), which also filtered very small reads (length $<15 \mathrm{bp}$ ). An alignment against the $A$. mellifera genome (assembly version 4.5) was run using TopHat (Trapnell et al., 2009) (v.2.0.7), guided by the respective RefSeq (Release 55) transcript coordinates. The genomic alignments were then submitted to Cufflinks (Trapnell et al., 2010) (v.2.0.2) for transcript assembly, estimation of their abundances and testing for differential expression between EcR$\mathrm{KD}$ and control samples. The Cufflinks procedures were also guided by the RefSeq transcript coordinates. The expression estimates were properly normalized considering ambiguous alignments, and corrected for fragment bias (Roberts et al., 2011). The Poisson fragment dispersion model was used in the comparison analysis. Cufflinks calculates the FPKM (Fragments Per Kilobase of exon per Million fragments mapped), log2-fold-change and $q$ value ( $p$-value adjusted by False Discovery Rate, FDR). However, the log2-fold-change was recalculated after adding an offset of 1 to FPKM values in order to enable comparison involving samples without expression (zero) and to reduce the variability of the log ratios for low expression values (less than one). The functional annotation was done using Blast2GO (Conesa et al., 2005) (v.2.5), InterProScan (Mulder and Apweiler, 2007) (v.5-RC6), RefSeq transcript annotation and finding the Reciprocal-Best-Hit of $A$. mellifera RefSeq proteins against D. melanogaster proteins database (FlyBase r5.49) using blastp. The Blast2GO annotation pipeline was run based on blastp results of RefSeq proteins against nr database.

Computational processing of the Small RNA-Seq reads comprised the following steps: (i) initial sequence quality filtering based on unidentified bases; (ii) rRNA read filtering based on matches against SILVA database (Release 115); (iii) sequence adapter clipping using CutAdapt and Scythe; (iv) read trimming based on quality scores, Ns and poly- $\mathrm{A}^{+}$tail prediction. All of these procedures were performed using PRINSEQ in the same way as described above. After each one of these preprocessing steps, an alignment against the $A$. mellifera genome (assembly version 4.5 ) was performed using the reads that had not already been aligned at each previous alignment step. Finally, all the alignment results were concatenated and transformed into a proper format to identify miRNAs. For this purpose, any splitted alignments were excluded.

Genomic alignments were performed using TopHat and the other alignments were performed using Bowtie2 (Langmead and Salzberg, 2012) (v.2.0.6). miRNA digital expression (MDE) levels were obtained by analysis with miRDeep2 (Friedländer et al., 2012) (v.2.0.0.5*), which provides the counts of reads mapped to the A. mellifera miRNA dataset in miRBase (Release 19). The original miRDeep2 code was modified to provide read counts for mature miRNAs instead of each precursor, and then the $\log 2$-fold-change was calculated and statistical significance was assessed using the method proposed by Audic and Claverie (1997) with adjustment by FDR.

\section{RESULTS}

\section{EcR-A AND EcR-B TRANSCRIPT VARIANT IDENTIFICATION IN HONEYBEES}

Two transcript variants, EcR-A (Accession numbers NM_001098215.2) and EcR-B (NM_001159355.1) of 2635 and 2782 nucleotides, respectively, have been identified for the A. mellifera EcR gene (Takeuchi et al., 2007 and Watanabe et al., 2010). The difference in nucleotide length was shown to reside within the $5^{\prime}$ end, resulting in amino acid sequence variation in the $\mathrm{N}$ - modulator $\mathrm{A} / \mathrm{B}$ domain. Conceptual translation of the nucleotide sequences resulted in a putative EcR-A protein consisting of 629 amino acid residues and an EcR-B protein of 557 amino acids, both sharing a 452 amino acid sequence in the carboxy terminal (Figure 1A). Northern blot analysis using a C-terminal EcR probe showed hybridization bands of approximately $2.7 \mathrm{~kb}$ and $2.6 \mathrm{~kb}$ (Figure 1B), mainly in queen samples, but since we did not aim at quantifying, the respective band 


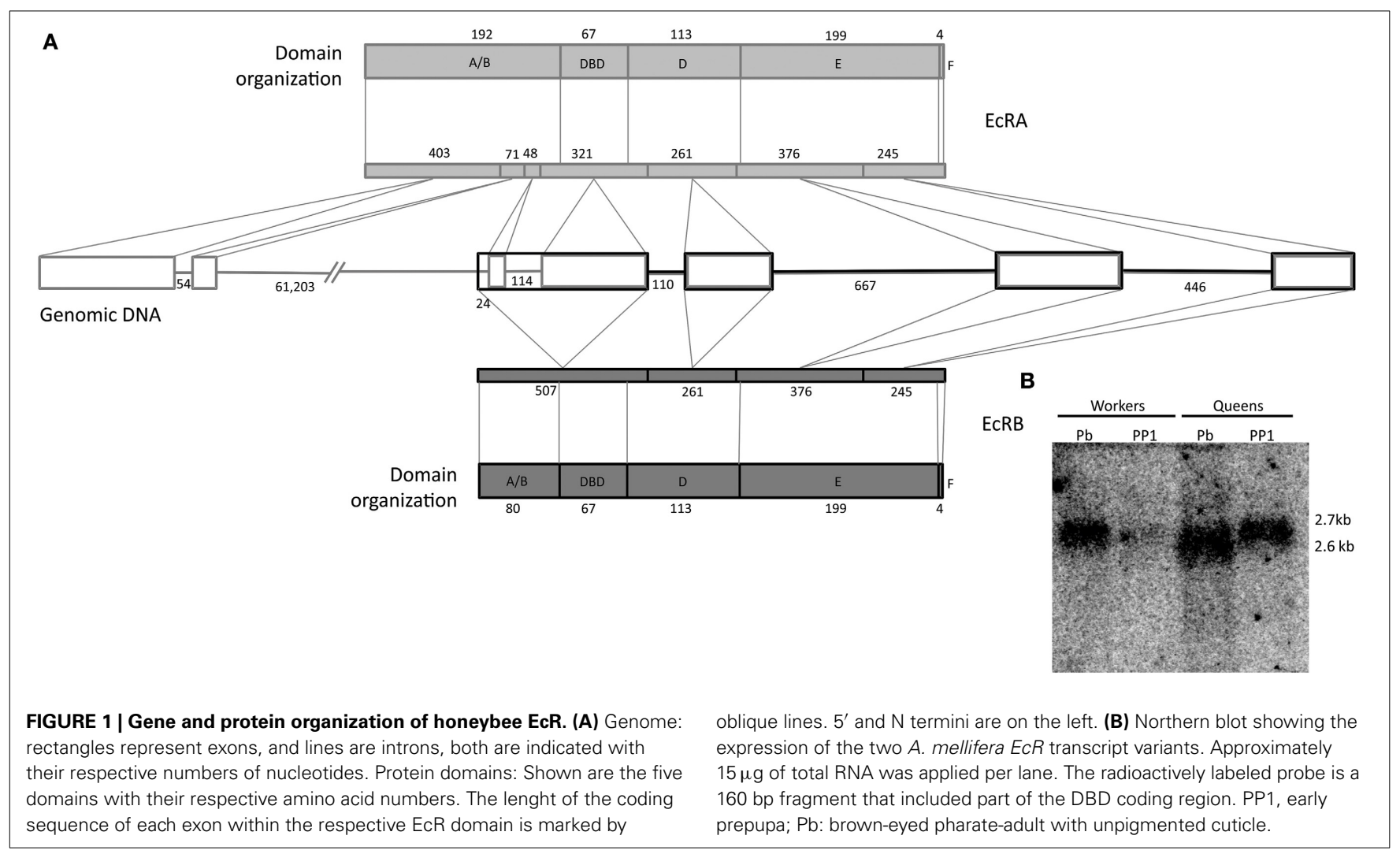

density does not necessarily represent difference in transcript levels between the two castes. Nonetheless, this result reveals that the two transcripts indeed have small differences in length, this supporting the in silico evidence.

\section{DEVELOPMENTAL PROFILES OF THE ECR TRANSCRIPT VARIANTS A AND B}

Using variant-specific primers we quantified the transcript levels of $E c R-A$ and $E c R-B$ covering the entire postembryonic development for honeybee queens and workers (Figure 2). Three major findings are worthy of note: (i) transcripts representing the EcR$B$ variant are predominant in embryos (Mann-Whitney Test, $P \leq 0.05$ ), but these transcript levels decline at the transition to the first larval instar, and it is the $E c R-A$ variant which is then predominantly expressed during the end of the larval stage (fifth instar) and pupal stage; (ii) at several time-points, EcR expression is higher in workers than in queens (Mann-Whitney Test, $P \leq 0.05$ ); and (iii) there is a clear discrepancy between circulating ecdysteroid levels and the developmental expression of EcR-A.

Major caste differences in EcR-A expression were seen to accompany the larval/pupal metamorphic molt. As soon as the larvae were no longer fed by nurse bees and the brood cells were closed, the EcR-A levels were increased by two orders of magnitude in cocoon-spinning worker larvae (S1-S3 phases). A rise was also seen in EcR-A levels in cocoon spinning queen larvae, but this was significantly lower than in workers (MannWhitney Test, $P \leq 0.05)$. A similar pattern was also seen for the EcR-B variant, but at much lower modulation. Interestingly, the EcR expression levels were then decreased for both variants and in both castes at the onset of the prepupal development (PP1), marked by the appearance of apolysis fluid separating the fifth instar larval cuticle from the newly synthesized pupal cuticle in the head region. A new rise in the transcript levels of both variants was then seen at the end of the prepupal development (PP3), but this was primarily evident in workers (MannWhitney Test, $P \leq 0.05)$. EcR-A and EcR-B transcript variants remained at low levels during the pupal and early pharate-adult stages ( $\mathrm{Pw}$ to $\mathrm{Pbl}$ phases) before they showed another steady increase, but again mainly so in workers (Mann-Whitney Test, $P \leq 0.05)$.

\section{TRANSCRIPTIONAL RESPONSE OF ECR TO ARTIFICIALLY AUGMENTED ECDYSTEROID AND JH TITERS}

So as to better understand the relationship between hemolymph hormone titers and hormone receptor expression, especially the remarkable divergence in the pupal stage, we treated $\mathrm{Pb}$-phase workers and queens, as these are at the transition from pupal development per se to the pharate adult stage, with $\mathrm{JH}$ and $20 \mathrm{E}$. At the $\mathrm{Pb}$-phase the ecdysteroid titer is rapidly declining in both castes after having gone through the maximum peak at the preceding Pp phase (Pinto et al., 2002), while JH levels are still basal (Rembold, 1987). The transcriptional responses for the two EcR variants assayed by RT-qPCR revealed a general repressive effect of both hormones at $24 \mathrm{~h}$ after application (Figure 3 ). In queens, $20 \mathrm{E}$ injection elicited a repressive effect on both EcR variants. 

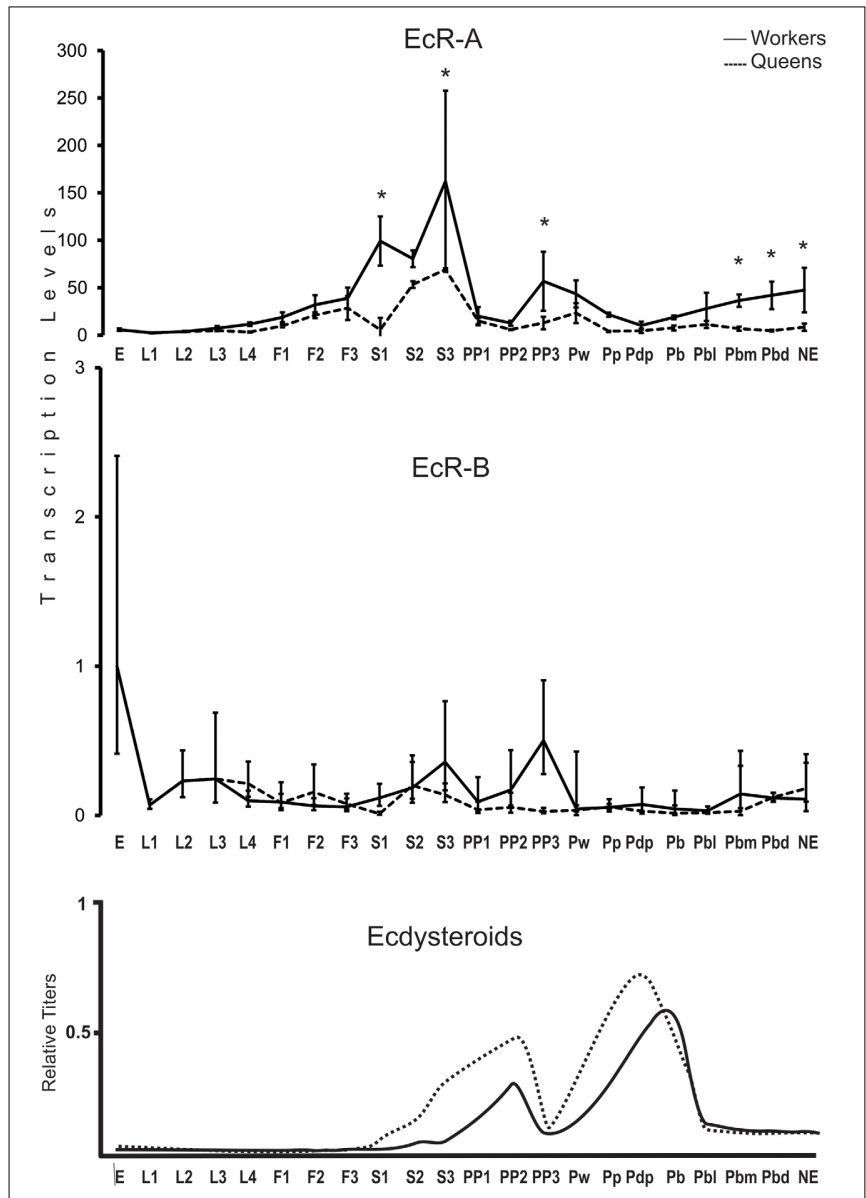

FIGURE 2 | Developmental expression profile of the $E c R$ gene in A. mellifera queens and workers. ECR-A and EcR-B transcript levels were measured by RT-qPCR. Bars represent means \pm S.E.M. of three biological replicates, each run as three technical replicates. Asterisks indicate a statistical difference (Mann-Whitney Test, $P \leq 0.05$ ) between queens and workers for the respective developmental phase. See Table 1 for a description of the developmental phases. Hormone titers are based on Rachinsky et al. (1990) and Pinto et al. (2002).

Mean transcript levels were diminished at $12 \mathrm{~h}$ after $20 \mathrm{E}$ injection and were significantly lower at $24 \mathrm{~h}$ (Mann-Whitney Test, $P \leq$ $0.05)$. In workers this was the case only for the $E c R-B$ transcript and only at $24 \mathrm{~h}$ (Figure 3A).

The effect of exogenous JH on EcR expression was not as clearcut as that elicited by $20 \mathrm{E}$ treatment. While there was no apparent effect on $E c R-A$ transcripts in workers, the $E c R-B$ levels showed slightly elevated means at all time points (Figure 3B), and these were significantly higher at $12 \mathrm{~h}$ following hormone treatment (Mann-Whitney Test, $P \leq 0.05$ ). Interestingly, in the queen caste the response to $\mathrm{JH}$ treatment appeared to be opposite to that seen in workers, with mean EcR-A and EcR-B transcript levels diminished already at $1 \mathrm{~h}$ after treatment and significant differences apparent at $1 \mathrm{~h}$ in the case of $E c R-B$ and at $24 \mathrm{~h}$ for $E c R-A$ (MannWhitney Test, $P \leq 0.05)$. These results indicate a repressor effect of high circulating ecdysteroid levels on $E c R$ expression in both castes and a differential response to $\mathrm{JH}$, with workers responding positively and queens negatively to elevated JH levels.

\section{ECR KNOCKDOWN IN PHARATE-ADULT HONEYBEE WORKERS SIGNIFICANTLY DOWNREGULATES THE EXPRESSION OF CANDIDATE TARGET GENES}

So as to understand the role of the $E c R$ gene in honeybee development, beyond the correlation analysis between transcript levels of the two EcR variants and hormone levels, we experimentally decreased the $E c R$ gene functionality by an RNA interference approach. We herein focused on the $E c R$ response in workers during the pharate-adult to adult transition because only one of the two transcript variants, viz. EcR-A, undergoes a gradual increase at this developmental interval, and only so in the worker caste (Figure 2). We expected this to give not only more clear-cut results and insights into the role of the predominant EcR variant, but also into still very little understood aspects of morphogenetic processes taking place in developing adult honeybees.

The dsRNA fragment used in this experiment represented an EcR region shared by the two transcript variants and its injection resulted in a reduction of 79.8 and $74.9 \%$ for $E c R-A$ and $E c R-B$ mRNA levels, respectively $(P<0.001$, Student's $t$ test; see Figure 4). A mortality of $10 \%$ was observed in both EcR- (KD) and GFP-dsRNA treated (control) bees. A proportion of dsRNA-injected bees showed alterations in cuticle pigmentation and wing development, similar to previously reported observations by Barchuk et al. (2008) when studying ultraspiracle function. Based on the strong knockdown response we next assayed the transcriptional response of four candidate target genes, these being a homolog of the D. melanogaster ftz- $f 1$ gene, the $v g$ gene, and two genes involved in adult cuticle formation (AmelCPR14 and BursA). The $f t z-f 1$ gene was included in this analysis because in D. melanogaster it acts as a competence factor for the response to 20E; furthermore, EcR also inhibits $f t z-f 1$ expression in D. melanogaster mid-prepupa, thus temporarily impairing the larval-to-pupal transition in response to the second 20E peak (King-Jones and Thummel, 2005). In pharate-adult honeybees, the levels of $f t z-f 1$ transcripts were seen to increase (data not shown) concomitantly with the levels of $E c R-A$, suggesting a synergistic action of the two genes. In addition, the increase in the levels of the two genes coincides with the increase in the expression of genes encoding enzymes and proteins needed for the complete differentiation of the adult cuticle (Soares et al., 2007, 2011, 2013; Elias-Neto et al., 2010). Similarly, in D. melanogaster the expression of $f t z-f 1$ has recently been related to adult cuticle formation and eclosion (Sultan et al., 2014). The analysis of $f t z-f 1$ transcript levels in newly emerged workers $(N=12)$, i.e., approximately 2 days after injecting dsRNAs, showed that $f t z-f 1$ expression was significantly decreased in EcR-KD bees ( $P \leq 0.05$, Student's $t$-test) (Figure 4). A significant effect of the EcR knockdown was also seen for the cuticular protein gene AmelCPR14, but not for the Burs A gene that encodes a subunit of the neurohormone Bursicon. The significant reduction in the expression of a cuticular protein gene following EcR-RNAi is consistent with the ecdysteroid-related expression of these genes in developing honeybees (Soares et al., 2007, 2011, 2013). An interesting though not easily explained finding was that $v g$ gene expression was not significantly affected by reducing EcR function, although the mean $v g$ transcript levels were slightly reduced 
A

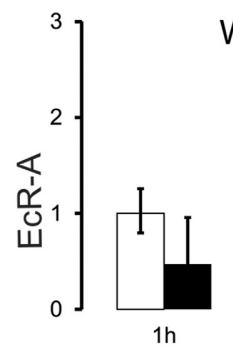

Workers/20E
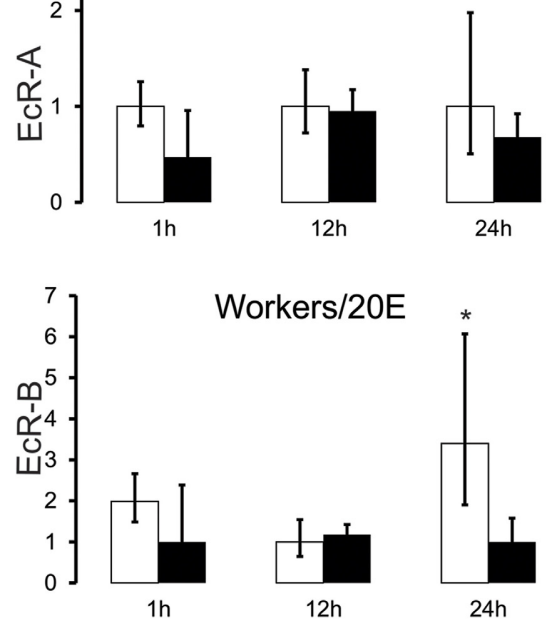

Workers/20E
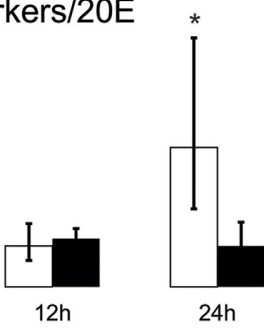

B
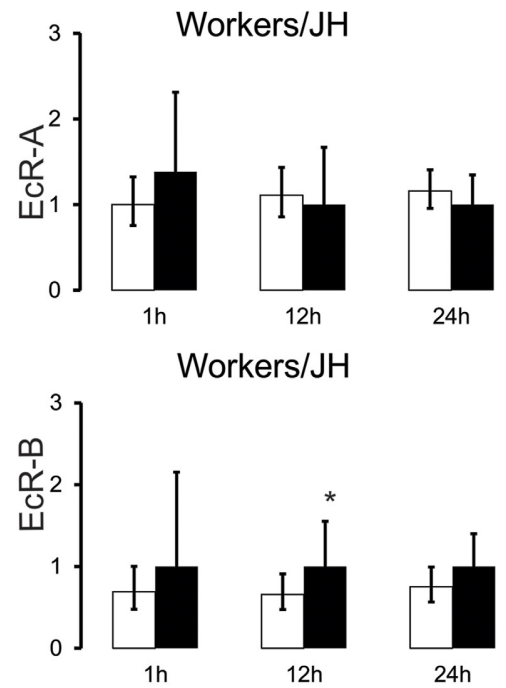

FIGURE 3 | EcR expression response to experimentally augmented levels of (A) 20-hydroxyedysone (20E) and (B) juvenile hormone (JH) in honeybee castes. Aliquots of $5 \mu \mathrm{g}$ of $20 \mathrm{E}$ or $10 \mu \mathrm{g}$ of $\mathrm{JH}-\mathrm{III}$ were applied to brown-eyed pharate-adults with unpigmented cuticle ( $\mathrm{Pb}$ phase). RNA

samples from fat bodies were obtained after 1, 12, and $24 \mathrm{~h}$ after hormone
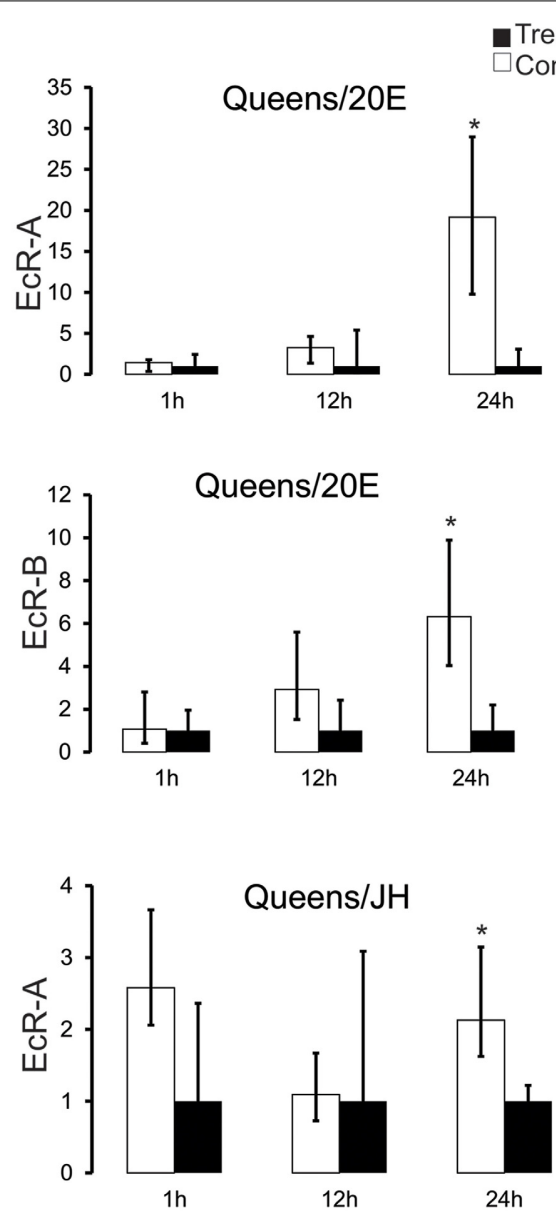

Queens/JH
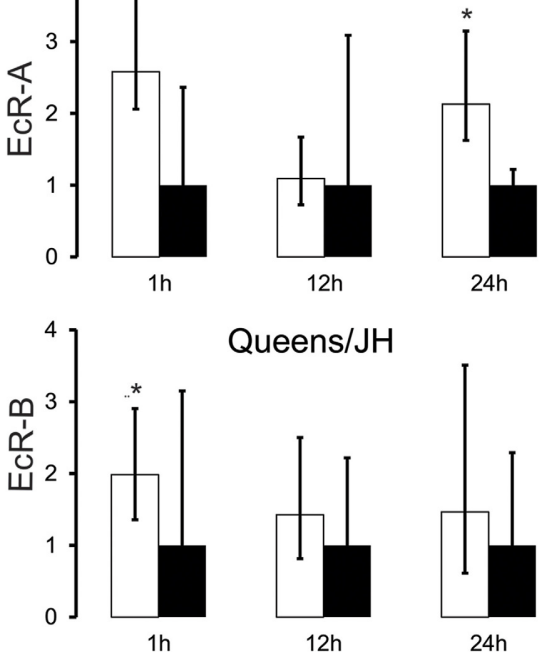

Queens/JH

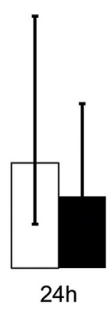

applications. Bars represent means \pm S.E.M. of three samples. Each biological replicate consisted of 3-7 Pb-phase workers and each was run as three technical replicates. Statistical differences $(* P=0.05)$ in gene expression between treated and control groups were assessed by Mann-Whitney Test.

compared to the non-target dsRNA control. This was surprising as $v g$ gene expression has been shown to gradually increase in pharate-adult honeybee females, and this increase was thought to be related to ecdysone levels (Barchuk et al., 2002; Piulachs et al., 2003).

\section{ECR KNOCKDOWN AFFECTS THE POLY-A+ PROFILE OF NEWLY EMERGED WORKERS}

So as to understand EcR functions during the pharate-adult to adult transition of honeybee workers on a more global scale we compared the poly- $\mathrm{A}^{+}$transcriptomes of EcR-KD and
GFP-injected (control) bees. After filtering of the raw data we obtained 112,659,148 reads for the $\mathrm{KD}$ and 71,050,536 reads for the control samples. Most of these reads were $50 \mathrm{nt}$ long. This data has been submitted to the Sequence Read Archive (SRA, NCBI, http://www.ncbi.nlm.nih.gov/sra) under the Accession Number SRX700299. As we had only one RNA sample set per group (two libraries, no replicates), the estimate obtained by Cuffdiff analysis was that 234 loci were differentially expressed [absolute log2 (fold change) $>1 ; q$-value $=0.05 ;$ FPKM $>5$ in at least one library] (Table S2). Among these, 121 code for known protein products, and 100 of these were upregulated in KD pharate-adults and 21 


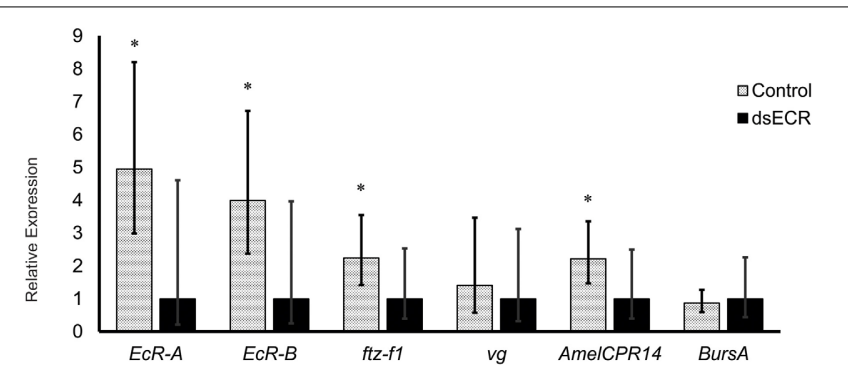

FIGURE 4 | Relative transcript levels of four candidate EcR-target genes following $\boldsymbol{E} \boldsymbol{c} \boldsymbol{R}$ knockdown in honeybee workers. Twelve

pharate-adult workers (Pbl phase) were injected with $5 \mu \mathrm{g}$ of EcR-dsRNA (KD) or GFP-dsRNA (C, control) and sampled just after adult eclosion. Bars represent means and S.E.M of 12 biological replicates, each run as three technical replicates. ${ }^{*}$ Indicates a statistically significant difference (Mann-Whitney Test, $P \leq 0.05$ ).

were downregulated (overexpressed in control bees; Table 2). The five times higher number of differentially expressed genes in the EcR-KD group indicates that during the pharate-adult to adult transition more genes may be repressed by ecdysone than are induced.

In terms of functional assignments the following conclusions can be drawn. Seven genes among the ones upregulated in the KD group code for cytochrome P450 proteins (Table 2 and Figure S1A), six of these belonging to CYP clade 3 (CYP6AS2, CYP6AS3, CYP6AS4, CYP6AS5, CYP6AS12, and CYP6BD1) and one (CYP305D1) to CYP clade 2 [for clade assignments of honeybee cytochrome P450 genes see (Claudianos et al., 2006)]. A second protein family that was well-represented among the upregulated genes in the KD group is that encoding Major Royal Jelly Proteins (MRJP1 and MRJP9) and an MRJP-associated protein, apisimin. A third class is represented by hormone responserelated genes: a gene encoding a $\mathrm{JH}$-inducible protein, a gene encoding a honeybee eclosion hormone (EH) homolog, and krüppel-homolog 1, an immediate response gene regulated by the JH receptor (Bellés and Santos, 2014). Nonetheless, the genes with the highest differential expression index are three genes encoding transcripts of unknown function and without conserved domain evidence (LOC100576540, LOC727013, and LOC727546). The fourth highest upregulated gene in the $\mathrm{KD}$ group encodes an $\alpha$-glucosidase, an enzyme that converts the disaccharide sucrose into glucose and fructose and is, thus, critically involved in carbohydrate metabolism. Another three genes in the top gene list are also related to metabolic functions, these being transcripts for a glycine $\mathrm{N}$-methyltransferase-like, a glycine-methanol-choline (GMC) oxidoreductase 3 and a lipase 3-like protein. Furthermore, three genes upregulated in $\mathrm{KD}$ bees, the GMC oxidoreductase 3, a UDP-glycosyltransferase (LOC 413043) and a glucuronosyltransferase (LOC 725997), could be related to ecdysteroid metabolism and function.

The genes downregulated in EcR-KD bees are listed at the bottom of Table 2. They are represented with positive fold change values, as these were calculated as relative to the control group. In contrast to the upregulated genes, those that were downregulated are not as clearly associated to putative functions during the pharate-adult to adult transition, except for the LOC724735 and Grp genes that encode structural cuticle proteins needed for the construction of the adult cuticle at this stage. The gene with the highest overexpression index in the control group codes for a Niemann-Pick type protein (NPC2), that is, genes involved in cholesterol metabolism-related syndromes and diseases (another $n p c 2$-type gene was found slightly overexpressed in the KD bees). Next are three transcripts possibly related to venom gland function, encoding a phospholipase, secapin and a putative mast cell degranulating peptide (Table 2 and Figure S1A). Also downregulated was the brown gene, which encodes an ABC-2 type transporter protein, and a gene coding for a Major Royal Jelly Protein (MRJP3).

A more global analysis on the entire set of differentially expressed genes was done based on Gene Ontology (Blast2GO and InterProScan) using Fisher and Kolmogorov-Smirnov statistics. This confirmed that the poly- $\mathrm{A}^{+}$RNAs representing genes upregulated in the KD group are enriched in proteins participating in metabolic pathways, particularly ones with catalytic and oxidoreductase activities (Table S3).

So as to validate the poly- $\mathrm{A}^{+}$RNA-sequencing results we then chose two genes revealed as upregulated in the $\mathrm{KD}$ group (Cyp6as5, a P450 protein coding gene, and $k r-h 1$, a gene encoding the $\mathrm{JH}$ response factor Krüppel homolog-1) and two downregulated genes (LOC406145, secp and LOC724386, npc2). For these we designed or selected from the literature gene-specific primers and ran RT-qPCR assays. The expression pattern was confirmed for all four genes (Figure S1A), thus providing further evidence that the 234 poly- $\mathrm{A}^{+}$RNA coding genes found as differentially expressed between treated and control bees are under EcR control.

\section{EcR KNOCKDOWN AFFECTS THE miRNA PROFILE OF NEWLY EMERGED WORKERS}

We obtained a total of 31,171,886 and 33,683,147 reads of small RNAs from the KD and control sequence libraries, respectively. This data has been submitted to the Sequence Read Archive (SRA, NCBI, http://www.ncbi.nlm.nih.gov/sra) under the Accession Number SRX700299. After filtering the raw data, we focused on the discovery of miRNAs linked to the EcR network. A total of $4,436,511$ reads of the KD samples $(\sim 13.2 \%)$ and $10,557,117$ reads of the control sample ( $\sim 33.9 \%)$ mapped to known honeybee mature miRNAs (available in miRBase version 19), suggesting that EcR disruption causes a general downregulation of miRNA families. We considered as "expressed" those miRNAs with more than 10 reads represented in at least one library. By doing so we retrieved a total of 132 known miRNAs expressed in newly emerged workers, most of them (124) in both conditions (Table S4). In order to find a set of miRNAs whose transcription is significantly affected by the EcR pathway, we filtered the Cuffdiff results by selecting miRNAs with expression differences higher than 1.2fold and a $q$-value $<0.05$ between KD and control bees. We found 60 downregulated and 10 upregulated miRNAs in KD samples compared to controls (Table 3). These data were then further validated by RT-qPCR assays for the following miRNAs: miR-14, miR-100, miR-125, miR-133, miR-375, miR-3728, and miR-3771 (Figure S1B). 
Table 2 | Protein-coding genes (121) that were differentially expressed in EcR knockdown (EcR-KD) bees (FC $\geq 2 ; q$-value $\leq 0.0015)$.

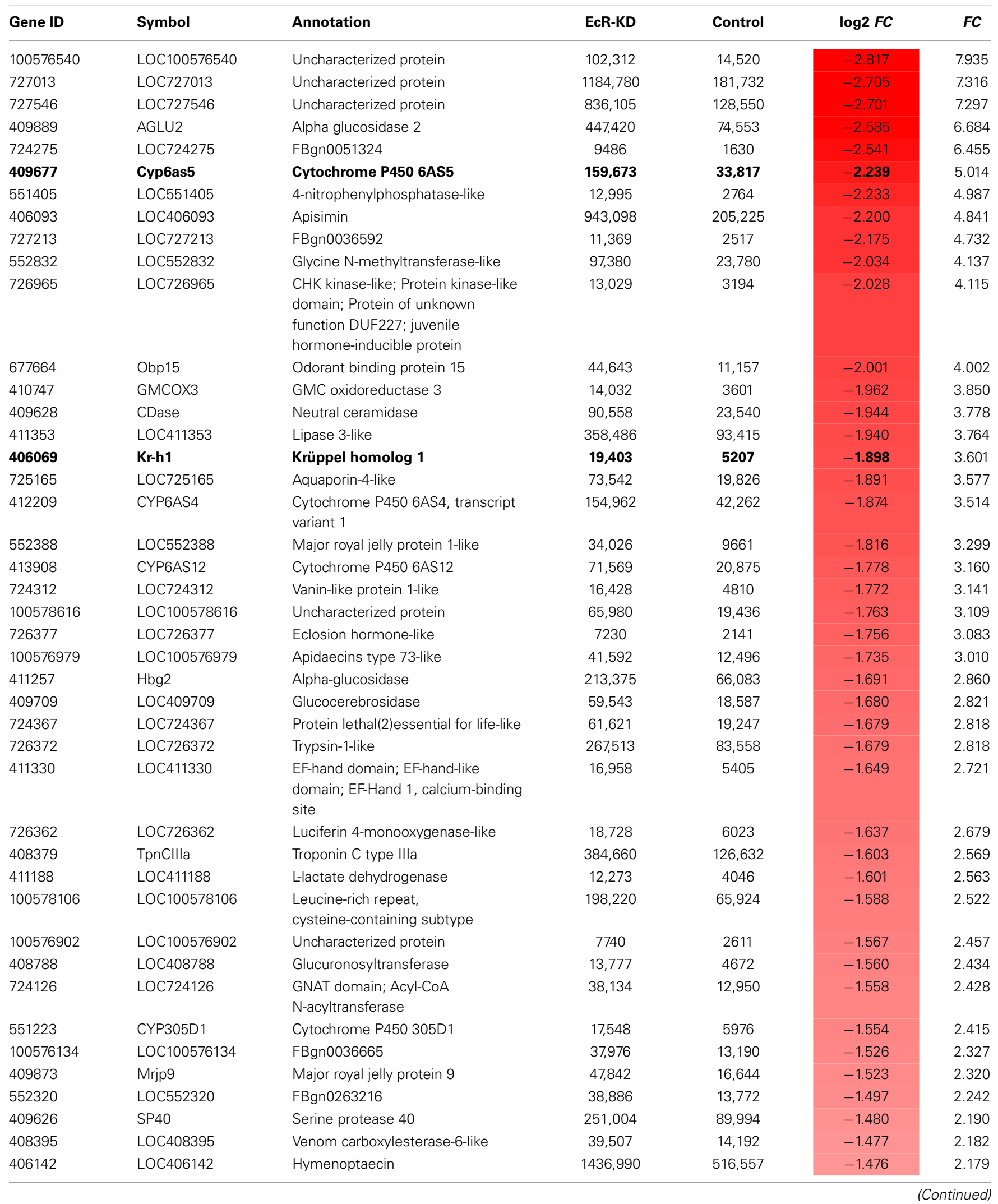


Table 2 | Continued

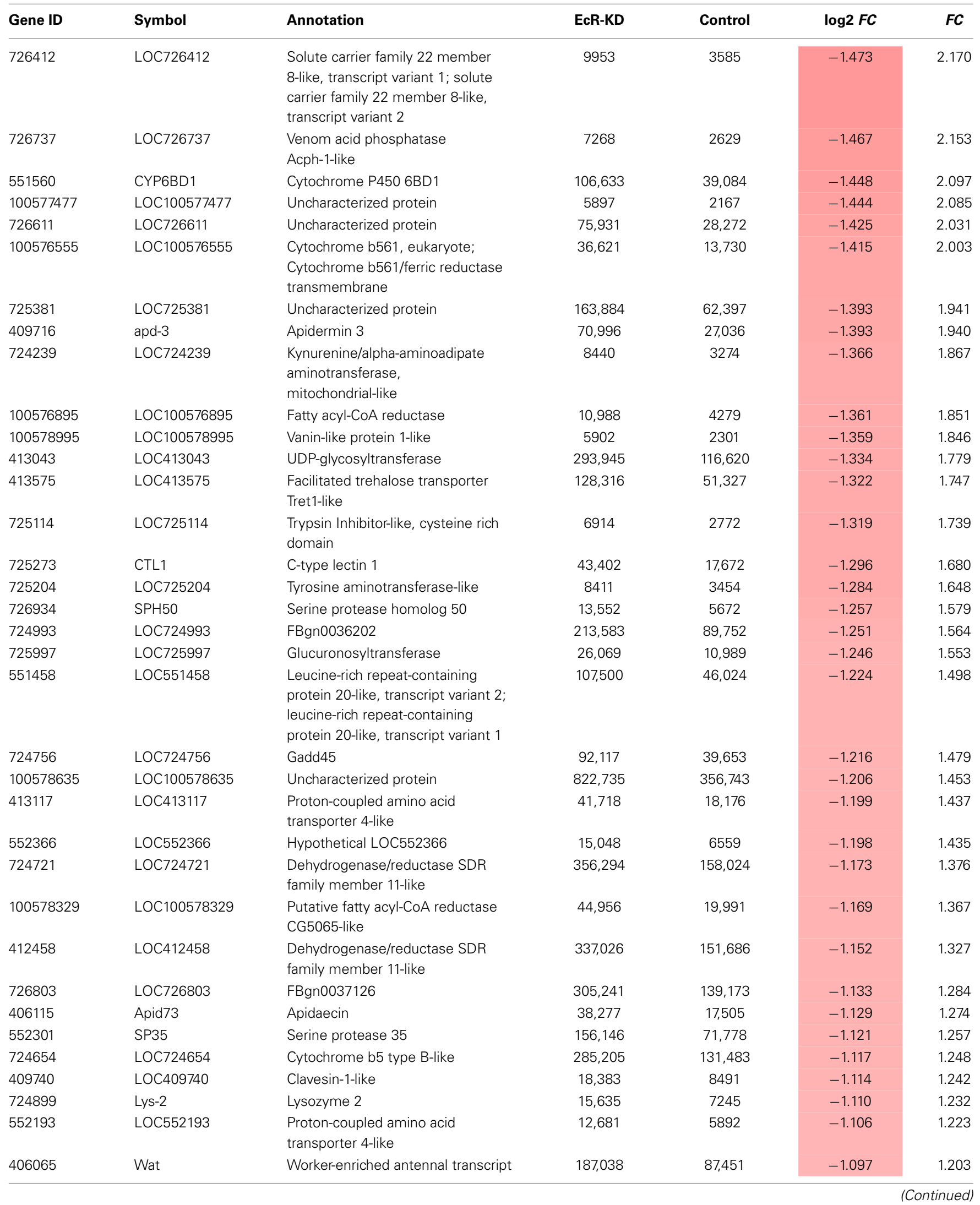


Table 2 | Continued

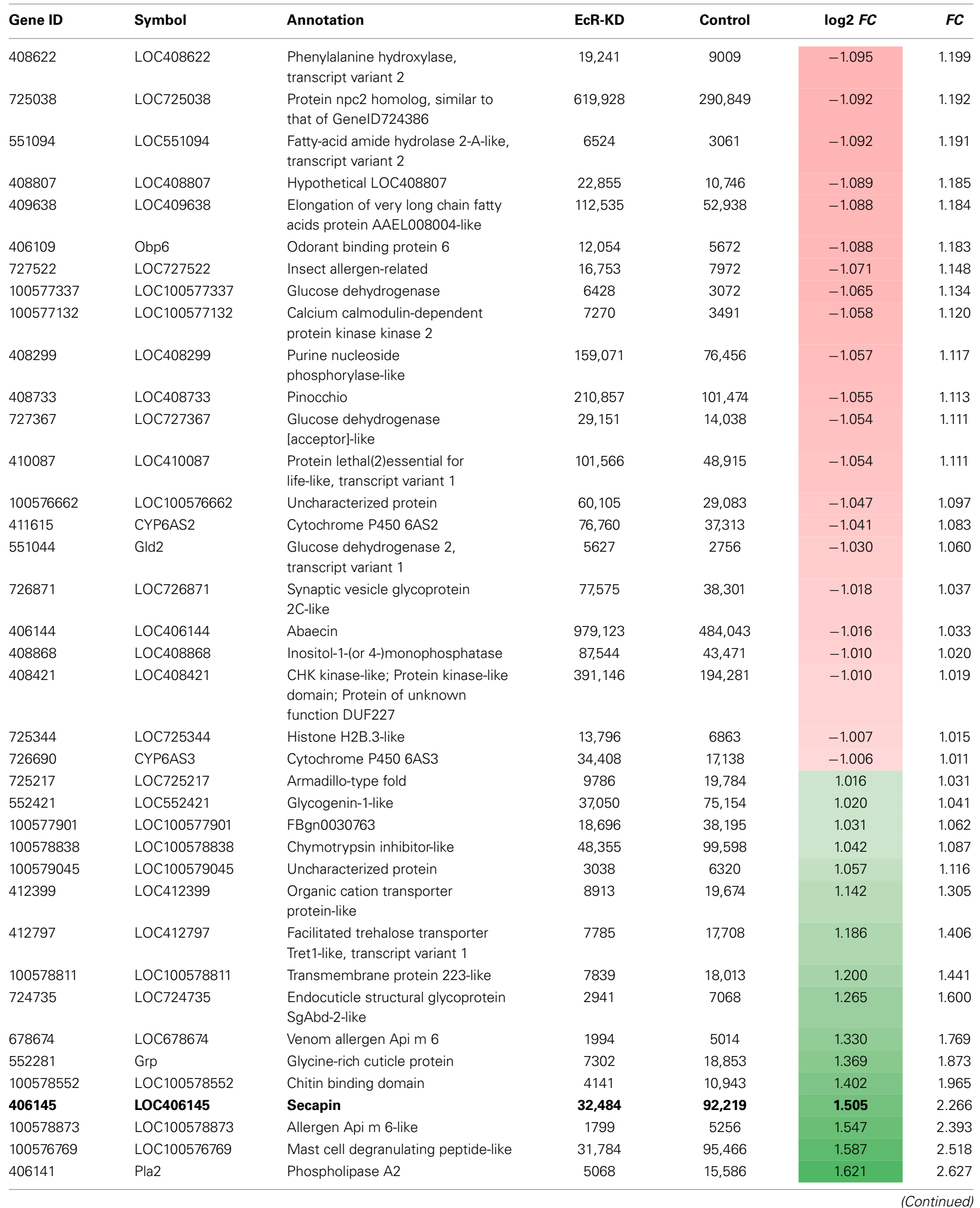


Table 2 | Continued

\begin{tabular}{|c|c|c|c|c|c|c|}
\hline Gene ID & Symbol & Annotation & EcR-KD & Control & $\log 2 F C$ & $F C$ \\
\hline 100578863 & LOC100578863 & Uncharacterized protein & 1641 & 5082 & 1.631 & 2.660 \\
\hline 725163 & LOC725163 & $\begin{array}{l}\text { Trypsin Inhibitor-like, cysteine rich } \\
\text { domain }\end{array}$ & 5520 & 22,669 & 2.038 & 4.153 \\
\hline 406121 & Mrjp3 & Major royal jelly protein 3 & 1102 & 5592 & 2.343 & 5.491 \\
\hline 412203 & bw & Brown & 1347 & 7074 & 2.392 & 5.724 \\
\hline 724386 & LOC724386 & Protein npc2 homolog & 757,358 & 4202,210 & 2.472 & 6.111 \\
\hline
\end{tabular}

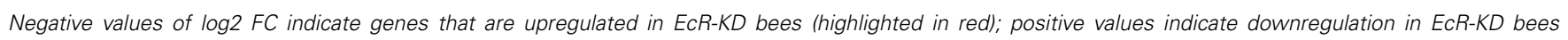

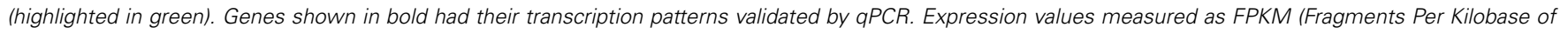
exon per Million fragments mapped). This list contains only the genes with FPKM values of 5 for any of the two samples.

\section{DISCUSSION \\ THE HONEYBEE ECR TRANSCRIPT VARIANTS AND THEIR DEVELOPMENTAL REGULATION}

The existence of more than one EcR isoform is commonplace in insects, including the honeybee, for which two transcript variants, $E c R-A$ and $E c R-B$ had been found (Takeuchi et al., 2007). First shown for D. melanogaster (Talbot et al., 1993) and then for the red flour beetle Tenebrio molitor (Mouillet et al., 1997), the extensive review of insect EcR isoforms by Watanabe et al. (2010) showed a high similarity in their nucleotide and amino acid sequences in most of their functional domains, except for the $\mathrm{N}$-terminal region including the variable $\mathrm{A} / \mathrm{B}$ modulator domain, which might allow for the recruitment of different co-activators/co-repressors (Tora et al., 1988; Kato et al., 1995; Watanabe et al., 2010).

First, we confirmed by northern blotting the expression of the two $E c R$ variants in honeybee queens and workers. Then, we compared their temporal expression profiles to the hemolymph ecdysteroid titers of fifth instar queen and worker larvae (F1-PP3 phases) (Rachinsky et al., 1990). The results for the developmental expression profiles of the two ecdysteroid receptor variants are surprising in two aspects. First, contrasting with the hormone titers, which are higher in queens than in workers, the EcR transcript levels were found to be higher in workers, especially so for $E c R-A$. Second, there was a marked drop in $E c R$ expression at the beginning of the prepupal phase (PP1), i.e., exactly when the hemolymph ecdysteroid levels increase to reach a developmental peak at the subsequent PP2 phase. Strikingly as well, the transcript levels for both EcR variants remained at low or basal levels during the pupal and early pharate-adult stages ( $\mathrm{Pw}$ to $\mathrm{Pbl}$ phases), even though the ecdysteroid hemolymph titers are at a maximum during this period (Feldlaufer et al., 1985; Pinto et al., 2002).

The switch from EcR-B expression in the embryonic stage to EcR-A as the predominant isoform in the fifth larval instar and pupal stage reflects a change in the processing of an eventual long pre-mRNA, or a shift in transcription start site utilization (our RNA-Seq data are in support of the latter possibility and even suggest the existence of a third EcR transcript variant). Since the $E c R$ gene is known to be induced after an ecdysteroid pulse (Karim and Thummel, 1992; Davis and Li, 2013), the production of $E c R-B$ mRNA in honeybee embryos would require the presence of steroid hormones, which is indeed the case. Makisterone
A, the predominant ecdysteroid in A. mellifera (Feldlaufer et al., 1985), has been shown to be present in ovaries in quite large amounts (Feldlaufer et al., 1986a), and unpublished data from our laboratory also confirm the presence of ecdysteroids in developing embryos. High levels of ecdysteroids in ovaries have also been shown for bumblebee queens (Geva et al., 2005) and queens of a swarm-founding neotropical wasp, Polybia micans (Kelstrup et al., 2014). Embryonic ecdysteroids can be synthesized by enzymatic conversion from inactive conjugates stored during oogenesis (Dorn, 2000) or, as seen in mosquitoes, transferred by males during copulation (Baldini et al., 2013).

Since makisterone A is the predominant ecdysteroid compound in queen ovaries (Feldlaufer et al., 1986a) and also in pupal-stage hemolymph (Feldlaufer et al., 1986b) and 20E is not negligible in prepupal hemolymph (Rachinsky et al., 1990), the observed embryonic-to-larval EcR isoform switch may be linked to variation in the ecdysteroid composition circulating in the hemolymph, throughout a bee's life cycle. This could not only be responsible for the observed differential $E c R$ transcription, but also for the formation of different hormone/receptor complexes with potentially different target genes thus, governing separate physiological processes. 20E, for example, might have retained a role in reproductive physiology, as suggested by Takeuchi et al. (2007), whereas makisterone A may have been co-opted for governing postembryonic development, as suggested for Dysdercus fasciatus (Feldlaufer et al., 1991). Nonetheless, for honeybees such "division of labor" in ecdysteroid compounds is still highly speculative, especially since the ecdysteroid hemolymph levels in adult honeybee queens and workers are continuously low, this making it rather unlikely that these steroid hormones may play a major role in the reproductive female physiology (Hartfelder et al., 2002). Instead, they seem to be preferentially stored in the developing follicles.

The second and third major findings mentioned above are that the $E c R-A$ transcript levels are higher in worker than in queen development, and that there is no positive, but rather an apparently negative correlation between hormone levels and hormone receptor transcript levels. This stands in stark contrast to the developmental pattern of the hemolymph ecdysteroid titers in the two castes, which are higher in queens than in workers, particularly so during larval-pupal metamorphosis (Rachinsky et al., 1990). The ecdysteroid titer in last instar queen larva rises as soon as the brood cells are closed and the larvae start to spin their 
Table 3 | miRNAs that were differentially expressed in EcR-knockdown bees.

\begin{tabular}{|c|c|c|c|c|c|c|}
\hline \multirow[t]{2}{*}{ Effect } & \multirow[t]{2}{*}{ miRNA } & \multicolumn{2}{|c|}{ Read counts } & \multicolumn{2}{|c|}{$\begin{array}{c}\text { Normalized number } \\
\text { of reads }\end{array}$} & \multirow[t]{2}{*}{ Fold change } \\
\hline & & Control & KD & Control & KD & \\
\hline \multirow{37}{*}{ 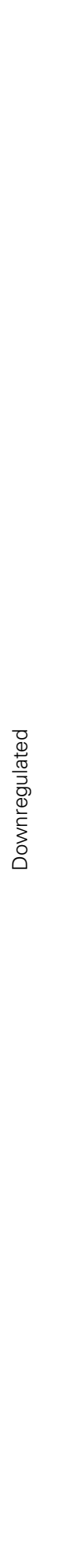 } & ame-miR-3771-3p & 12 & 1 & 0.79 & 0.13 & 6.06 \\
\hline & ame-miR-6067-5p & 19 & 2 & 1.25 & 0.25 & 4.99 \\
\hline & ame-miR-6046-3p & 31 & 6 & 2.04 & 0.76 & 2.68 \\
\hline & ame-miR-3770-5p & 57 & 14 & 3.75 & 1.78 & 2.11 \\
\hline & ame-miR-133-3p & 7726 & 2092 & 508.90 & 265.35 & 1.92 \\
\hline & ame-miR-375-3p & 64,153 & 17,597 & 4225.66 & 2232.01 & 1.89 \\
\hline & ame-miR-1-3p & 78,433 & 21,559 & 5166.27 & 2734.56 & 1.89 \\
\hline & ame-miR-6043-3p & 352 & 98 & 23.19 & 12.43 & 1.87 \\
\hline & ame-miR-927a-5p & 129,279 & 40,144 & 8515.42 & 5091.89 & 1.67 \\
\hline & ame-miR-971-3p & 110 & 35 & 7.25 & 4.44 & 1.64 \\
\hline & ame-miR-87-3p & 14,514 & 4783 & 956.02 & 606.68 & 1.58 \\
\hline & ame-miR-263a-5p & 857,064 & 283,563 & $56,453.55$ & $35,967.31$ & 1.57 \\
\hline & ame-miR-137-3p & 3351 & 1119 & 220.73 & 141.93 & 1.56 \\
\hline & ame-miR-1175-3p & 2179 & 731 & 143.53 & 92.72 & 1.55 \\
\hline & ame-miR-210-3p & 3330 & 1121 & 219.34 & 142.19 & 1.55 \\
\hline & ame-miR-316-5p & 21,370 & 7287 & 1407.61 & 924.29 & 1.53 \\
\hline & ame-miR-6038-5p & 445 & 158 & 29.31 & 20.04 & 1.46 \\
\hline & ame-miR-219-5p & 70 & 25 & 4.61 & 3.17 & 1.45 \\
\hline & ame-miR-980-3p & 235 & 86 & 15.48 & 10.91 & 1.41 \\
\hline & ame-miR-184-3p & $1,460,229$ & 568,579 & $96,183.15$ & $72,118.91$ & 1.34 \\
\hline & ame-miR-6041-3p & 95 & 37 & 6.26 & 4.69 & 1.34 \\
\hline & ame-miR-252b-5p & 420 & 164 & 27.66 & 20.80 & 1.33 \\
\hline & ame-miR-3747b-5p & 793 & 310 & 52.23 & 39.32 & 1.33 \\
\hline & ame-miR-2788-3p & 1137 & 445 & 74.89 & 56.44 & 1.33 \\
\hline & ame-miR-317-3p & 6091 & 2391 & 401.21 & 303.28 & 1.32 \\
\hline & ame-miR-6012-3p & 122 & 48 & 8.04 & 6.09 & 1.32 \\
\hline & ame-miR-3791-3p & 697 & 277 & 45.91 & 35.13 & 1.31 \\
\hline & ame-miR-71-5p & 1667 & 660 & 109.80 & 83.71 & 1.31 \\
\hline & ame-miR-34-5p & 3245 & 1289 & 213.74 & 163.50 & 1.31 \\
\hline & ame-miR-3718a-3p & 3817 & 1517 & 251.42 & 192.42 & 1.31 \\
\hline & ame-miR-927b-5p & 3108 & 1250 & 204.72 & 158.55 & 1.29 \\
\hline & ame-miR-929-5p & 3423 & 1379 & 225.47 & 174.91 & 1.29 \\
\hline & ame-miR-305-5p & 62,480 & 25,699 & 4115.47 & 3259.68 & 1.27 \\
\hline & ame-miR-124-3p & 2142 & 882 & 141.09 & 111.87 & 1.26 \\
\hline & ame-miR-996-3p & 44,757 & 18,495 & 2948.08 & 2345.92 & 1.26 \\
\hline & ame-miR-10-5p & $1,146,362$ & 477,869 & $75,509.19$ & $60,613.20$ & 1.25 \\
\hline & ame-miR-276-3p & 808,220 & 339,646 & $53,236.27$ & $43,080.91$ & 1.24 \\
\hline
\end{tabular}




\begin{tabular}{|c|c|c|c|c|c|c|}
\hline \multirow[t]{2}{*}{ Effect } & \multirow[t]{2}{*}{ miRNA } & \multicolumn{2}{|c|}{ Read counts } & \multicolumn{2}{|c|}{$\begin{array}{c}\text { Normalized number } \\
\text { of reads }\end{array}$} & \multirow[t]{2}{*}{ Fold change } \\
\hline & & Control & KD & Control & KD & \\
\hline & ame-miR-3477-5p & 46,537 & 19,658 & 3065.32 & 2493.43 & 1.23 \\
\hline & ame-miR-6001-5p & 173 & 73 & 11.40 & 9.26 & 1.23 \\
\hline & ame-miR-283-5p & 42,234 & 17,884 & 2781.89 & 2268.42 & 1.22 \\
\hline & ame-miR-263b-5p & 41,279 & 17,642 & 2718.99 & 2237.72 & 1.21 \\
\hline & ame-miR-14-3p & 94,785 & 40,489 & 6243.35 & 5135.65 & 1.21 \\
\hline & ame-miR-79-3p & 3701 & 1589 & 243.78 & 201.55 & 1.21 \\
\hline & ame-miR-3719-3p & 2799 & 1217 & 184.37 & 154.37 & 1.20 \\
\hline & ame-miR-12-5p & 89,841 & 38,948 & 5917.70 & 4940.19 & 1.20 \\
\hline & ame-miR-279b-3p & 650 & 281 & 42.81 & 35.64 & 1.20 \\
\hline & ame-miR-6039-5p & 494 & 214 & 32.54 & 27.14 & 1.20 \\
\hline & ame-miR-6051-3p & 343 & 149 & 22.59 & 18.90 & 1.20 \\
\hline \multirow{10}{*}{ 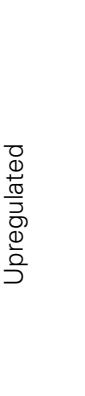 } & ame-miR-3728-5p & 105 & 124 & 6.92 & 15.73 & 2.27 \\
\hline & ame-miR-965-5p & 21 & 20 & 1.38 & 2.54 & 1.84 \\
\hline & ame-miR-6005-3p & 76 & 64 & 5.01 & 8.12 & 1.62 \\
\hline & ame-miR-3798-3p & 342 & 259 & 22.53 & 32.85 & 1.45 \\
\hline & ame-miR-6052-5p & 43 & 31 & 2.83 & 3.93 & 1.39 \\
\hline & ame-miR-3761-5p & 342 & 232 & 22.53 & 29.43 & 1.31 \\
\hline & ame-miR-3720-5p & 1586 & 1004 & 104.47 & 127.35 & 1.22 \\
\hline & ame-miR-6001-3p & 27,917 & 17,745 & $1,838.85$ & 2250.79 & 1.22 \\
\hline & ame-miR-306-5p & 186,621 & 117,263 & $12,292.45$ & $14,873.71$ & 1.21 \\
\hline & ame-miR-9a-5p & 88,013 & 55,087 & 5797.29 & 6987.27 & 1.21 \\
\hline
\end{tabular}

Only miRNAs with Fold-change $>1.2$ are listed.

cocoons (S1-stage), while in workers this was only seen in the late spinning (S3) to early prepupal (PP1) phases. Furthermore, the peak in edysteroid levels reached during the prepupal phase (PP2) is twice as high in queens compared to workers (Rachinsky et al., 1990). The negative correlation between ecdysteroid levels and $E c R$ expression is particularly evident at two time points: in prepupae, when ecdysteroid levels are high in the PP1-PP2 phases, just as the EcR-A expression pattern undergoes a valley, and in the pupal stage, when the ecdysteroid levels are high in both castes at the $\mathrm{Pp}$ phase, before dropping in the $\mathrm{Pb}-\mathrm{Pbl}$ phases (Pinto et al., 2002). It is only after this drop in circulating hormone levels that $E c R-A$ transcription is resumed, particularly so in the worker caste, and strikingly, it is during the subsequent $\mathrm{Pbm}$ and Pbd phases that the ecdysteroid levels are again lower in workers than in queens (Pinto et al., 2002).

This apparent negative correlation between hormone and hormone receptor levels was suggestive of a repressive action of high concentrations of circulating ecdysteroids on the expression of their receptor gene. To test this we manipulated the endogenous hormone levels by treating $\mathrm{Pb}$ pharate-adults with either $20 \mathrm{E}$ or $\mathrm{JH}$. The results of the $20 \mathrm{E}$ injection experiments showed that a prolonged and excessive presence of ecdysteroids had a repressive effect on EcR-A and EcR-B expression, especially so in queens (Figure 3A). Interestingly, workers seem to be more resilient to this repressor effect, as there was no significant reduction in EcRA transcript levels, comparable to that seen in queens, or for
EcR-B in both castes. Such resilience was also denoted in the JH application experiment, where EcR-A transcript levels in workers remained little affected compared to those in queens and for EcR-B in both castes $24 \mathrm{~h}$ after the $20 \mathrm{E}$ injection. Strikingly, JH appeared to have opposite effects on EcR-B expression in the two female castes, showing a positive effect in workers and a negative one in queens. These differences of hormone effects on $E c R$ expression related to caste certainly deserve a closer look in future experiments.

Repressive effects of high concentrations of ecdysteroids on EcR-expression are, however, not new and are likely to be a general feature of hormone systems that underly cyclical events in morphogenesis and physiology. For instance, similar results were described for Manduca sexta, where low concentrations of $20 \mathrm{E}$ induced $E c R$ expression while high concentrations repressed the expression of this gene (Jindra et al., 1996). Like ours, these results suggest that the $E c R$ gene responds positively to a slight increase in ecdysteroids, whereas high hormone levels are repressive. In fact, as we could see, $E c R$ expression actually appears to precede the rise in hormone levels, for instance in the S1-S3 phases, when the circulating ecdysteroid levels start increasing (Rachinsky et al., 1990), but EcR-A and also EcR-B transcript levels have already undergone a steep rise. A repetition of this pattern can be inferred for the pupal ecdysis event, occurring between PP3 and Pw, when the ecdysteroid titers undergo a sharp drop, but EcR-A and EcR-B are on the rise (mainly in workers), and drop once the ecdysteroid 
titers build up to maximal values in the Pp phase. It is such cyclical events, the molts, that are synchronized by the ecdysone/ecdysone receptor complex action, and this is primarily seen in the epidermis, the main organ of cuticle synthesis. In the honeybee, several cuticle protein genes were shown to be regulated by ecdysteroids (Soares et al., 2007, 2011, 2013; Elias-Neto et al., 2010).

\section{RNAi-MEDIATED KNOCKDOWN REVEALS EcR REGULATED GENES IN DEVELOPING ADULTS}

Upon comparing the sequencing results of the poly- $\mathrm{A}^{+}$libraries for EcR knockdown (EcR-KD) and control groups, the Cutdiff analysis classified 234 loci as differentially expressed. Among these, 121 were annotated as coding for known protein products or, from another point of view, 113, i.e., one half, represent loci for unknown, not annotated products, which could be either proteins or long non-coding RNAs. Especially the latter are still "dark matter" in the honeybee genome, represented by many ESTs in the databases, but only four long non-coding RNAs are so far characterized to some detail (Sawata et al., 2002; Humann et al., 2013).

Among the genes with known orthologs or sequence similarity in functional domains, 100 were overexpressed (fold change $>1$ ) in the EcR-KD group and 21 in the control group, this indicating that apparently more genes are repressed by the ecdysone/EcR receptor complex than are activated. Furthermore, a Gene Ontology and KEGG pathway analysis showed that there is little overlap in gene functions between the two sets of differentially expressed genes (DEGs). As mentioned above, cytochrome P450 genes are strongly represented among the DEGs. While cytochrome $\mathrm{P} 450$ genes are a large gene family, strongly related to detoxification processes, this family has undergone considerable reduction in honeybee genome evolution (Claudianos et al., 2006). This reduction is, however, denoted only in certain clades of the P450 enzymes, but not in the clades comprising the genes found in our EcR-RNAi experiment. Unfortunately, there is no further functional or tissue/cell type information available for the five cytochrome $\mathrm{P} 450$ genes, especially whether or not they may be related to steroid synthesis or metabolism. Nonetheless, similar findings as the ones we report here were also denoted by Davis and Li (2013) in their genomic screen for ecdysone and EcR-dependent gene expression in D. melanogaster.

A second group of overrepresented genes that called attention was the hormone response-related genes, as these may provide a link between $\mathrm{JH}$ and ecdysteroid action during the pharate-adult to adult transition in honeybees. For this group we found three genes as overexpressed in the EcR-KD group, viz. a JH-induced protein, $k r-h 1$, and an Eclosion hormone-like (EH-like) gene. $k r$ $h 1$ is certainly the most interesting gene in this set, as it represents a direct readout of the activity of the $\mathrm{JH}$ response in target tissues (Lozano and Belles, 2011; Bellés and Santos, 2014). As kr-h1 has previously been identified in a screen for ecdysone-response genes in D. melanogaster (Beckstead et al., 2005), the current identification of this gene in the EcR-KD group provides experimental evidence toward a mechanistic explanation for the modulation of vitellogenin induction in honeybee pharate-adults, where $v g$ expression is caste-specifically induced by $\mathrm{JH}$ and counteracted by ecdysteroids (Barchuk et al., 2002). Overexpression of an EH-like gene in the EcR-KD group was not unexpected, as EH is synthesized in response to declining ecdysteroid titers and is part of the ecdysis triggering signaling cascade (Zitnan and Adams, 2012). Interestingly, other three upregulated genes in EcR-KD bees may have roles in ecdysteroid metabolism and function. Several GMC oxidoreductase genes in diverse insects, including A. mellifera, are clustered in an evolutionary conserved tandem array with potential to be co-regulated for a common function related to ecdysteroid metabolism (Iida et al., 2007). The products of LOC413043 and LOC725997 may regulate ecdysteroid titer and function since the enzymes encoded by these genes catalyze the transfer of glucose from UDP-glucose to ecdysteroids, and thus are possibly related to ecdysteroid inactivation (O'Reilly and Miller, 1989).

Overexpression of members of the Major Royal Jelly Protein (MRJP) family can be interpreted in the context of a repressive action of the ecdysone/EcR receptor complex on genes of the adult honeybee life cycle (the only exception being the gene coding for the MRJP3, which was overexpressed in control bees). The mrjp gene family with its nine members is a lineage-specific extension in the genus Apis, from a single mrjp-like gene within the yellow genes complex (Drapeau et al., 2006). Even though these proteins are highly expressed in the hypopharyngeal glands of nurse worker bees, constituting the major protein fraction of the glandular secretions fed to larvae (royal jelly and worker jelly), expression of the mrjp genes is neither exclusive to this tissue nor is it restricted to the worker caste. Especially mrjp9 has been shown to be broadly expressed, in different tissues of adult workers and also in queens and even drones (Buttstedt et al., 2013). In contrast to mrjp9, mrjpl expression is more tissue-specific, being highest in heads (viz. hypopharyngeal glands) of nurse bees, with expression levels being considerably lower in other body parts, castes and sexes (Buttstedt et al., 2013). MRJP1 is the predominant MRJP moiety in royal jelly, present as oligomers of MRJP1 subunits, which are held together by apisimin, a small $5 \mathrm{kDa}$ protein (Tamura et al., 2009). ESTs corresponding to apisimin were found as overrepresented in the EcR-KDS group, indicating that its expression is co-regulated with that of mrjp1. But this coregulation is not due to genomic proximity, as the mrjp/yellow gene cluster maps to chromosome 11, whereas apisimin is located in chromosome 6. Interestingly, an MRJP1 monomer, royalactin, was found to be an important factor in caste development, acting through the Egfr signaling pathway (Kamakura, 2011).

Among the EcR-KD group genes we also identified obp15, which encodes a putative odorant binding protein. Some $o b p$ genes were also found to be under negative EcR control in D. melanogaster, including the obp15 and obp6 genes (Davis and Li, 2013). Forêt and Maleszka (2006) had previously shown that obp15 is expressed in the antennae of adult bees and also in young larvae but not in pupae. The high ecdysteroid levels in honeybee hemolymph during the pupal to pharate-adult transition, thus, appear to repress obp15 expression, and possibly also other members of this complex gene family.

Among the genes overrepresented in the transcriptome of the control group (downregulated in EcR-KD bees), the first in the top ten list is annotated as $n p c 2$. Genes of this family are associated with Niemann-Pick syndromes and diseases affecting 
cholesterol metabolism (Carstea et al., 1997). In D. melanogaster, NPC mutations cause intracellular enrichment of cholesterol, reduced ecdysteroidogenesis and death in the first larval instar. The fact that this condition could be fully rescued when an excess of dietary cholesterol was given to these mutants indicated that the ecdysone biosynthesis pathway is intact, but precursor processing is not (Huang et al., 2007). Interestingly, in honeybees, as in other insects, the major ecdysteroid is not ecdysone or its derivative 20E, but makisterone A, an ecdysteroid methylated at C24 (Feldlaufer et al., 1985, 1986a,b; Rachinsky et al., 1990), possibly due to a lack or restriction in C24-demethylation of a phytosterol precursor. The expression of two other genes overrepresented in the transcriptome of the control group has been shown to be dependent on the ecdysteroid titer. The protein encoded by LOC724735, an endocuticle structural protein (Márcia M. G. Bitondi, unpublished results) and also the Grp gene, renamed as tweedle1 (AmelTwdl1) (Soares et al., 2011), were induced in the integument by the ecdysteroid pulse that promotes the pupal to pharate-adult transition. Thus, the functionality of the ecdysone/EcR complex is necessary for the activation of these genes. Interestingly, mrjp3, the third among the genes overrepresented in control bees (and thus induced by the EcR pathway), encodes one of the main MRJPs produced by nurse bees (Buttstedt et al., 2013). The mrjp3 gene thus seems to be highly expressed by the time of adult emergence and the first days of adult life. Unlike the mrjp1 and mrjp2 genes, mrjp3 reaches negligible expression levels in foragers, which, together with its distinctive amino acid sequence (Drapeau et al., 2006), supports the notion of its main function as food protein supplier to larvae by nurse bees. However, the fact that mrjp1, another MRJP gene highly expressed in nurse bees, was found to be repressed by the ecdysteroid pathway (see above), suggests the mrjp3 gene is regulated in a distinct mode from the other mrjp genes.

\section{miRNAs AS ACTORS IN THE EcR REGULATORY NETWORK}

Here we demonstrate that the RNAi-mediated knockdown of $E c R$ function perturbs the expression of 70 miRNAs $(\sim 1 / 3$ of the honeybee miRNAs known to date). Most of these (60) were downregulated and 10 were upregulated and we assume that these down and upregulated miRNAs are "induced" or "repressed," respectively, by the EcR pathway as bees undergo the pharate-adult to adult transition.

Among the miRNAs that showed significant changes in abundance following EcR knockdown, most had already been identified in a large-scale sequencing project (Chen et al., 2010), but had no function(s) associated. Our data now lead to infer that these miRNAs are, at least, closely associated with EcR action and, consequently, connected to pupal-adult metamorphosis. In addition to these miRNAs of yet unclear functions, we also found conserved and functionally well-defined miRNAs, such as let-7, miR-1, miR-133, miR-375, miR-184, and miR-34. For example, miR-133 and miR-1 are both clustered in the mouse and fly genomes, and they play important roles in muscle development and differentiation in vertebrates and invertebrates (Sokol and Ambros, 2005; Chen et al., 2006; Boutz et al., 2007). In the honeybee, however, we found these two miRNAs to be located far apart from one another on chromosome 16. Nonetheless, they still seem to be linked in their cooperative functions, such as formation and physiology of flight muscle tissue. miR-133 has also been implicated in dopamine production (Yang et al., 2014), and high levels of dopamine were shown to coincide with rapid growth and compartmentalization of the antennal lobe neuropil, suggesting a role in the developing brain of the honeybee (Kirchhof et al., 1999). Furthermore, dopamine-derivatives are substrates for oxidation by laccases (Andersen, 2010) that are involved in tanning of the developing adult cuticle (Elias-Neto et al., 2010). Members of the D. melanogaster let-7-C locus (a cluster containing the let7, miR-100, and miR-125 genes) are also found in the honeybee genome. In D. melanogaster they are expressed in neuromusculature development of pupae and adults, and knockout flies showed disturbances in flight, reproduction and locomotion (Sokol et al., 2008). Moreover, ecdysteroid signaling was shown to be linked to the expression levels of the let-7-C cluster genes, as well as of miR-14 and miR-34 during insect development (for review see Kucherenko and Shcherbata, 2013).

Many of the miRNAs affected by EcR knockdown in honeybees (let-7, miR-1, miR-9a, miR-12, miR-14, miR-34, miR-79, miR92b, miR-124, miR-184, miR-210, miR-219, miR-263a, miR-276, miR-279, miR-283, miR-305, miR-306, miR-316, miR-317) have previously been reported as putatively involved in the regulation of $D$. melanogaster immune genes, particularly those belonging to the JNK, Imd and Toll signaling pathways (Fullaondo and Lee, 2012). Accordingly, ecdysone and the ecdysone receptor complex (EcR/USP) are considered critical for innate cellular immunity (Flatt et al., 2008; Regan et al., 2013). Among these miRNAs, miR184 is highly and/or broadly expressed in a number of tissues and developmental stages of vertebrates (Wienholds and Plasterk, 2005) and invertebrates (Jagadeeswaran et al., 2010), including A. mellifera (Chen et al., 2010; Nunes et al., 2013b). Moreover, several studies reported a wide spectrum of roles for miR-184, such as germline differentiation, axis formation of the egg chamber, anteroposterior patterning and cellularization of the embryo, gastrulation and neuroectoderm formation, apoptosis, and processes involved in the development and differentiation of imaginal discs (head, wing, and eyes) (see Iovino et al., 2009; Li et al., 2011, and references therein). The ecdysone response of miR-184 seen here in pharate-adult honeybees is associated with a period of extensive tissue remodeling, suggesting that miR-184 may play a role in the differentiation of honeybee imaginal disc-derived structures and maintenance of their tissue identities. Interestingly, the EcR mRNA has predicted binding sites for miR-14 (data not shown), and our global gene expression assays revealed a downregulation of this miRNA in bees silenced for $E c R$ gene function. These results suggest that in $A$. mellifera, EcR gene expression is regulated in a loop-type mechanism involving miR-14, as already demonstrated for D. melanogaster (Varghese and Cohen, 2007; for a comprehensive review see Yamanaka et al., 2013).

\section{CONCLUDING REMARKS}

Our results suggest a differential use of EcR isoforms during the honeybee life-cycle stages. We could show that there is a generally positive $E c R$ gene response to slight increases in ecdysteroids, whereas high levels of these hormones are repressive. The EcR knockdown experiments revealed that the expression of 
several hormone response-related genes (e.g., $k r-h 1$ ) is contingent on a functional ecdysone/EcR receptor complex, thus providing a possible link between $\mathrm{JH}$ and ecdysteroid action during preimaginal honeybee development. These knockdown experiments also hightlighted the relevance of a set of miRNAs involved in the regulation of immune response genes and in the general morphogenesis processes during pharate-adult development (e.g., miR-184 and let-7 locus genes). Within this framework and on the background of current knowledge on honeybee biology, our results highlight the relevance of the drop in the ecdysteroid pathway function for the appropriate timing in the expression of adult-specific genes, such as the Major Royal Jelly Protein (MRJP) family members.

\section{AUTHOR CONTRIBUTIONS}

Tathyana R. P. Mello, Aline C. Aleixo, Angel R. Barchuk, and Zilá L. P. Simões conceived the project; Tathyana R. P. Mello, Aline C. Aleixo, Daniel G. Pinheiro, Francis M. F. Nunes, Klaus Hartfelder, and Angel R. Barchuk performed the experiments; Tathyana R. P. Mello, Aline C. Aleixo, Daniel G. Pinheiro, Francis M. F. Nunes, Márcia M. G. Bitondi, Klaus Hartfelder, Angel R. Barchuk, and Zilá L. P. Simões analyzed and interpreted the data and drafted the MS. All authors approved the final version of the MS.

\section{FUNDING}

This study was funded by the Fundação de Amparo à Pesquisa do Estado de São Paulo (FAPESP), grants 2011/03171-5; 2008/14464; 2008/10757-3.

\section{ACKNOWLEDGMENTS}

We thank Dr. Nilce M. M. Rossi, Roseli de Aquino P. Ferreira and Diana Gras for lab facility and support in Northern blotting assays, and Luiz Aguiar for technical assistance in the apiary. We also thank Felipe Martelli, Denyse C. Lago, Fabiano Abreu, and Camilla Valente Pires for help with the qPCR assays.

\section{SUPPLEMENTARY MATERIAL}

The Supplementary Material for this article can be found online at: http://journal.frontiersin.org/journal/10.3389/fgene. 2014.00445/abstract

\section{REFERENCES}

Amdam, G. V., Simões, Z. L. P., Guidugli, K. R., Norberg, K., and Omholt, S. W. (2003). Disruption of vitellogenin gene function in adult honeybees by intra-abdominal injection of double-stranded RNA. BMC Biotechnol. 3:e1. doi: 10.1186/1472-6750-3-1

Andersen, S. O. (2010). Insect cuticular sclerotization: a review. Insect Biochem. Mol. Biol. 40, 166-178. doi: 10.1016/j.ibmb.2009.10.007

Ashburner, M., Chihara, C., Meltzer, P., and Richards, G. (1974). Temporal control of puffing activity in polytene chromosomes. Cold Spring Harb. Symp. Quant. Biol. 38, 655-662. doi: 10.1101/SQB.1974.038.01.070

Audic, S., and Claverie, J. M. (1997). The significance of digital gene expression profiles. Genome Res. 7, 986-995.

Baldini, F., Gabrieli, P., South, A., Valim, C., Mancini, F., and Catteruccia, F. (2013). The interaction between a sexually transferred steroid hormone and a female protein regulates oogenesis in the malaria mosquito Anopheles gambiae. PLoS Biol. 11:e1001695. doi: 10.1371/journal.pbio.1001695

Barchuk, A. R., Bitondi, M. M. G., and Simões, Z. L. P. (2002). Effects of juvenile hormone and ecdysone on the timing of vitellogenin appearance in hemolymph of queen and worker pupae of Apis mellifera. J. Insect Sci. 2, 1-8. doi: $10.1673 / 031.002 .0101$
Barchuk, A. R., Cristino, A. S., Kucharski, R., Costa, L. F., Simões, Z. L. P., and Maleszka, R. (2007). Molecular determinants of caste differentiation in the highly eusocial honeybee Apis mellifera. BMC Dev. Biol. 7:70. doi: 10.1186/1471213X-7-70

Barchuk, A. R., Figueiredo, V. L. C., and Simões, Z. L. P. (2008). Downregulation of ultraspiracle gene expression delays pupal development in honeybees. J. Insect Physiol. 54, 1035-1040. doi: 10.1016/j.jinsphys.2008.04.006

Barchuk, A. R., Maleszka, R., and Simões, Z. L. P. (2004). Apis mellifera ultraspiracle: cDNA sequence and rapid up-regulation by juvenile hormone. Insect Mol. Biol. 13, 459-467. doi: 10.1111/j.0962-1075.2004.00506.x

Beckstead, R. B., Lam, G., and Thummel, C. S. (2005). The genomic response to 20-hydroxyecdysone at the onset of Drosophila metamorphosis. Genome Biol. 6:R99. doi: 10.1186/gb-2005-6-12-r99

Bellés, X., and Santos, C. G. (2014). The MEKRE93 (Methoprene tolerant-Krüppel homolog 1-E93) pathway in the regulation of insect metamorphosis, and the homology of the pupal stage. Insect Biochem. Mol. Biol. 52, 60-68. doi: 10.1016/j.ibmb.2014.06.009

Boutz, P. L., Chawla, G., Stoilov, P., and Black, D. L. (2007). MicroRNAs regulate the expression of the alternative splicing factor $\mathrm{nPTB}$ during muscle development. Genes Dev. 21, 71-84. doi: 10.1101/gad.1500707

Buffalo, V. (2011). Scythe. Available online at: https://github.com/vsbuffalo/scythe Buttstedt, A., Moritz, R. F. A., and Erler, S. (2013). More than royal food - Major royal jelly protein genes in sexuals and workers of the honeybee Apis mellifera. Front. Zool. 10:e72. doi: 10.1186/1742-9994-10-72

Carstea, E. D., Morris, J. A., Coleman, K. G., Loftus, S. K., Zhang, D., Cummings, C., et al. (1997). Niemann-Pick C1 disease gene: homology to mediators of cholesterol homeostasis. Science 277, 228-231. doi: 10.1126/science.277.53 23.228

Charles, J.-P., Iwema, T., Epa, V. C., Takaki, K., Rynes, J., and Jindra, M. (2011). Ligand-binding properties of a juvenile hormone receptor, Methoprene-tolerant. Proc. Natl. Acad. Sci. U.S.A. 108, 21128-21133. doi: 10.1073/pnas.1116123109

Chawla, G., and Sokol, N. S. (2012). Hormonal activation of let-7-C microRNAs via EcR is required for adult Drosophila melanogaster morphology and function. Development 139, 1788-1797. doi: 10.1242/dev.077743

Chen, J.-F., Mandel, E. M., Thomson, J. M., Wu, Q., Callis, T. E., Hammond, S. M., et al. (2006). The role of microRNA-1 and microRNA-133 in skeletal muscle proliferation and differentiation. Nat. Genet. 38, 228-233. doi: 10.1038/ng1725

Chen, X., Yu, X., Cai, Y., Zheng, H., Yu, D., Liu, G., et al. (2010). Nextgeneration small RNA sequencing for microRNAs profiling in the honey bee Apis mellifera. Insect Mol. Biol. 19, 799-805. doi: 10.1111/j.1365-2583.2010. 01039.x

Claudianos, C., Ranson, H., Johnson, R. M., Biswas, S., Schuler, M. A., Berenbaum, M. R., et al. (2006). A deficit of detoxification enzymes: pesticide sensitivity and environmental response in the honeybee. Insect Mol. Biol. 15, 615-636. doi: 10.1111/j.1365-2583.2006.00672.x

Conesa, A., Götz, S., García-Gómez, J. M., Terol, J., Talón, M., and Robles, M. (2005). Blast2GO: a universal tool for annotation, visualization and analysis in functional genomics research. Bioinformatics 21, 3674-3676. doi: 10.1093/bioinformatics/bti610

Davis, M. B., and Li, T. (2013). Genomic analysis of the ecdysone steroid signal at metamorphosis onset using ecdysoneless and EcRnull Drosophila melanogaster mutants. Genes Genomics 35, 21-46. doi: 10.1007/s13258-013-0061-0

Dorn, A. (2000). "Arthropoda-insecta: embryology," in Reproductive Biology of Invertebrates - Progress in Developmental Endocrinology, Vol. 10, Part B, ed A. Dorn (Chichester: Wiley \& Sons), 72-116.

Drapeau, M. D., Albert, S., Kucharski, R., Prusko, C., and Maleszka, R. (2006). Evolution of the yellow/major royal jelly protein family and the emergence of social behavior in honey bees. Genome Res. 16, 1385-1394. doi: 10.1101/gr.5012006

Elias-Neto, M., Soares, M. P. M., Simões, Z. L. P., Hartfelder, K., and Bitondi, M. M. G. (2010). Developmental characterization, function and regulation of a Laccase2 encoding gene in the honey bee, Apis mellifera (Hymenoptera, Apinae). Insect Biochem. Mol. Biol. 40, 241-251. doi: 10.1016/j.ibmb.2010. 02.004

Evans, R. M., and Mangelsdorf, D. J. (2014). Nuclear receptors, RXR, and the Big Bang. Cell 157, 255-266. doi: 10.1016/j.cell.2014.03.012

Fahrbach, S. E., Smagghe, G., and Velarde, R. A. (2012). Insect nuclear receptors. Annu. Rev. Entomol. 57, 83-106. doi: 10.1146/annurev-ento-120710-100607 
Feldlaufer, M. F., Herbert, E. W. J., and Svoboda, J. A. (1985). Makisterone A: the major ecdysteroid from the pupae of the honey bee, Apis mellifera. Insect Biochem. 15, 597-600. doi: 10.1016/0020-1790(85)90120-9

Feldlaufer, M. F., Herbert, E. W. Jr., Svoboda, J. A., and Thompson, M. J. (1986b). Biosynthesis of makisterone A and 20-hydroxyecdysone from labeled sterols by the honey bee, Apis mellifera. Arch. Insect Biochem. Physiol. 3, 415-421. doi: 10.1002/arch.940030502

Feldlaufer, M. F., Svoboda, J. A., and Herbert, E.W. Jr. (1986a). Makisterone A and 24-methylenecholesterol from the ovaries of the honey bee, Apis mellifera L. Experientia 42, 200-201. doi: 10.1007/BF01952468

Feldlaufer, M. F., Weirich, G. F., Lusby, W. R., and Svoboda, J. A. (1991). Makisterone C a 29-carbon ecdysteroid from developing embryos of the cotton stainer bug, Dysdercus fasciatus. Arch. Insect Biochem. Physiol. 18, 71-79. doi: 10.1002/arch.940180202

Flatt, T., Heyland, A., Rus, F., Porpiglia, E., Sherlock, C., Yamamoto, R., et al. (2008). Hormonal regulation of the humoral innate immune response in Drosophila melanogaster. J. Exp. Biol. 211, 2712-2724. doi: 10.1242/jeb.014878

Flatt, T., Tu, M. P., and Tatar, M. (2005). Hormonal pleiotropy and the juvenile hormone regulation of Drosophila development and life history. Bioessays 27, 999-1010. doi: 10.1002/bies.20290

Forêt, S., and Maleszka, R. (2006). Function and evolution of a gene family encoding odorant binding-like proteins in a social insect, the honey bee (Apis mellifera). Genome Res. 16, 1404-1413. doi: 10.1101/gr.5075706

Friedländer, M. R., Mackowiak, S. D., Li, N., Chen, W., and Rajewsky, N. (2012). miRDeep 2 accurately identifies known and hundreds of novel microRNA genes in seven animal clades. Nucleic Acids Res. 40, 37-52. doi: 10.1093/nar/gkr688

Fullaondo, A., and Lee, S. Y. (2012). Identification of putative miRNA involved in Drosophila melanogaster immune response. Dev. Comp. Immunol. 36, 267-273. doi: 10.1016/j.dci.2011.03.034

Gáliková, M., Klepsatel, P., Senti, G., and Flatt, T. (2011). Steroid hormone regulation of C. elegans and Drosophila aging and life history. Exp. Gerontol. 46, 141-147. doi: 10.1016/j.exger.2010.08.021

Geva, S., Hartfelder, K., and Bloch, G. (2005). Reproductive division of labor, dominance, and ecdysteroid levels in hemolymph and ovary of the bumble bee Bombus terrestris. J. Insect Physiol. 51, 811-823. doi: 10.1016/j.jinsphys.2005. 03.009

Hartfelder, K., Bitondi, M. M. G., Santana, W. C., and Simões, Z. L. P. (2002). Ecdysteroid titers and reproduction in queens and workers of the honey bee and of a stingless bee: loss of ecdysteroid function at increasing levels of sociality? Insect. Mol. Biol. 32, 211-216. doi: 10.1016/S0965-1748(01)00100-X

Hartfelder, K., and Emlen, D. (2012). "Endocrine control of insect polyphenism," in Insect Endocrinology, ed L. I. Gilbert (San Diego, CA: Academic Press), 464-522.

Hartfelder, K., and Engels, W. (1998). Social insect polymorphism: hormonal regulation of plasticity in development and reproduction in the honeybee. Curr. Top. Dev. Biol. 40, 45-77. doi: 10.1016/S0070-2153(08)60364-6

Hill, R. J., Billas, I. M. L., Bonneton, F., Graham, L. D., and Lawrence, M. C. (2013). Ecdysone receptors: from the Ashburner model to structural biology. Annu. Rev. Entomol. 58, 251-271. doi: 10.1146/annurev-ento-120811-153610

Huang, X., Suyama, K., Buchnan, J., Zhu, A. J., and Scott, M. P. (2007). A Drosophila model of the Niemann-Pick type C lysosome storage disease: dnpcla is required for molting and sterol homeostasis. Development 132, 5115-5124. doi: 10.1242/dev.02079

Humann, F. C., Tiberio, G. J., and Hartfelder, K. (2013). Sequence and expression characteristics of long noncoding RNAs in honey bee caste development - potential novel regulators for transgressive ovary size. PLoS ONE 8:e78915. doi: 10.1371/journal.pone.0078915

Iga, M., and Kataoka, H. (2012). Recent studies on insect hormone metabolic pathways mediated by Cytochrome P450 enzymes. Biol. Pharm. Bull. 35, 838-843. doi: 10.1248/bpb.35.838

Iida, K., Cox-Foster, D. L., Yang, X., Ko, W.-Y., and Cavener, D. R. (2007). Expansion and evolution of insect GMC oxidoreductases. BMC Evol. Biol. 7:75. doi: 10.1186/1471-2148-7-75

Iovino, N., Pane, A., and Gaul, U. (2009). miR-184 has multiple roles in Drosophila female germline development. Dev. Cell 17, 123-133. doi: 10.1016/j.devcel.2009. 06.008

Jagadeeswaran, G., Zheng, Y., Sumathipala, N., Jiang, H., Arrese, E. L., Soulages, J. L., et al. (2010). Deep sequencing of small RNA libraries reveals dynamic regulation of conserved and novel microRNAs and microRNA-stars during silkworm development. BMC Genomics 11:52. doi: 10.1186/1471-2164-11-52
Jindra, M., Malone, F., Hiruma, K., and Riddiford, L. M. (1996). Developmentl profiles and edysteroid regulation of the mRNAs for two edysone receptor isofroms in the epidermis and wings of the tobacco hornworm, Manduca sexta. Dev. Biol. 180, 258-272. doi: 10.1006/dbio.1996.0299

Kamakura, M. (2011). Royalactin induces queen differentiation in honeybees. Nature 473, 478-483. doi: 10.1038/nature10093

Karim, F. D., and Thummel, C. S. (1992). Temporal coordination of regulatory gene expression by the steroid hormone ecdysone. EMBO J. 11, 4083-4093.

Kato, S., Endoh, H., Masuhiro, Y., Kitamoto, T., and Uchiyama, S., Sasaki H., et al. (1995). Activation of the estrogen receptor through phosphorylation by mitogen-activated protein kinase. Science 270, 1491-1494. doi: 10.1126/science.270.5241.1491

Kelstrup, H., Hartfelder, K., Nascimento, F. S., and Riddiford, L. M. (2014). Reproductive status, endocrine physiology and chemical signaling in the Neotropical, swarm-founding eusocial wasp Polybia micans Ducke (Vespidae: Epiponini). J. Exp. Biol. 217, 2399-2410. doi: 10.1242/jeb.096750

King-Jones, K., and Thummel, C. S. (2005). Nuclear receptors, a perspective e from Drosophila. Nat. Rev. Genet. 6, 311-323. doi: 10.1038/nrg1581

Kirchhof, B. S., Homberg, U., and Mercer, A. R. (1999). Development of dopamineimmunoreactive neurons associated with the antennal lobes of the honey bee, Apis mellifera. J. Comp. Neurol. 411, 643-653.

Kucherenko, M. M., and Shcherbata, H. R. (2013). Steroids as external temporal codes act via microRNAs and cooperate with cytokines in differential neurogenesis. Fly 7, 173-183. doi: 10.4161/fly.25241

Langmead, B., and Salzberg, S. L. (2012). Fast gapped-read alignment with Bowtie 2. Nat Methods 9, 357-359. doi: 10.1038/nmeth.1923

Li, P., Peng, J., Hu, J., Xu, Z., Xie, W., and Yuan, L. (2011). Localized expression pattern of miR-184 in Drosophila. Mol. Biol. Rep. 38, 355-358. doi: 10.1007/s11033-010-0115-1

Lozano, J., and Belles, X. (2011). Conserved repressive function of Krüppel homolog 1 on insect metamorphosis in hemimetabolous and holometabolous species. Sci. Rep. 1:e163. doi: 10.1038/srep00163

Martin, M. (2011). Cutadapt removes adapter sequences from high-throughput sequencing reads. EMBnet J. 17, 10-12. doi: 10.14806/ej.17.1.200

Michelette, E. R. F., and Soares, A. E. E. (1993). Characterization of preimaginal developmental stages of Africanized honey bee workers (Apis mellifera L.). Apidologie 24, 431-440. doi: 10.1051/apido:19930410

Mouillet, J. F., Delbecque, J. P., Quennedey, B., and Delachambre, J. (1997). Cloning of two putative ecdysteroid receptor isoforms from Tenebrio molitor and their developmental expression in the epidermis during metamorphosis. Eur. J. Biochem. 248, 856-863. doi: 10.1111/j.1432-1033.1997.00856.x

Mulder, N., and Apweiler, R. (2007). InterPro and InterProScan: tools for protein sequence classification and comparison. Methods Mol. Biol. 396, 59-70. doi: 10.1007/978-1-59745-515-2_5

Nunes, F. M. F., Aleixo, A., Barchuk, A. R., Bomtorin, A. D., Grozinger, C., and Simões, Z. L. P. (2013a). Non-target effects of Green Fluorescent Protein (GFP)-derived double-stranded RNA (dsRNA-GFP) used in honey bee RNA interference (RNAi) assays. Insects 4, 90-103. doi: 10.3390/insects4010090

Nunes, F. M. F., Ihle, K. E., Mutti, N. S., Simões, Z. L. P., and Amdam, G. V. (2013b). The gene vitellogenin affects microRNA regulation in honey bee (Apis mellifera) fat body and brain. J. Exp. Biol. 216, 3724-3732. doi: 10.1242/jeb. 089243

O'Reilly, D. R., and Miller, L. R. (1989). A baculovirus blocks insect molting by producing ecdysteroid UDP-glucosyl transferase. Science 245, 1110-1112.

Ono, H. (2014). Ecdysone differentially regulates metamorphic timing relative to20-hydroxyecdysone by antagonizing juvenile hormone in Drosophila melanogaster. Dev. Biol. 391, 32-42. doi: 10.1016/j.ydbio.2014.04.004

Petryk, A., Warren, J. T., Marques, G., Jarcho, M. P., Gilbert, L. I., Kahler, J., et al. (2003). Shade is the p450 enzyme that mediates the hydroxylation of ecdysone to the steroid insect molting hormone 20-hydroxyecdysone. Proc. Natl. Acad. Sci. U.S.A. 100, 13773-13778. doi: 10.1073/pnas.2336088100

Pinto, L. Z., Hartfelder, K., Bitondi, M. M. G., and Simões, Z. L. P. (2002). Ecdysteroid titers in pupae of highly social bees relate to distinct modes of caste development. J. Insect Physiol. 48, 783-790. doi: 10.1016/S0022-1910(02) 00103-8

Piulachs, M. D., Guidugli, K. R., Barchuk, A. R., Cruz, J., Simões, Z. L. P., and Bellés, X. (2003). The vitellogenin of the honey bee, Apis mellifera: structural analysis of the cDNA and expression studies. Insect Biochem. Mol. Biol. 33, 459-465. doi: 10.1016/S0965-1748(03)00021-3 
Rachinsky, A., Strambi, C., Strambi, A., and Hartfelder, K. (1990). Caste and metamorphosis - hemolymph titers of juvenile hormone and ecdysteroids in last instar honeybee larvae. Gen. Comp. Endocrinol. 79, 31-38. doi: 10.1016/00166480(90)90085-Z

Regan, J. C., Brandão, A. S., Leitão, A. B., Mantas, D. A. R., Sucena, E., Jacinto, A., et al. (2013). Steroid hormone signaling is essential to regulate innate immune cells and fight bacterial infection in Drosophila. PLoS Pathog. 9:e1003720. doi: 10.1371/journal.ppat.1003720

Rembold, H. (1987). Caste-specific modulation of juvenile hormone titers in Apis mellifera. Insect Biochem. 17, 1003-1006. doi: 10.1016/0020-1790(87) 90110-7

Roberts, A., Trapnell, C., Donaghey, J., Rinn, J. L., and Pachter, L. (2011). Improving RNA-seq expression estimates by correcting for fragment bias. Genome Biol. 12:R22. doi: 10.1186/gb-2011-12-3-r22

Rubio, M., and Bellés, X. (2013). Subtle roles of microRNAs let-7, miR100 and miR-125 on wing morphogenesis in hemimetabolan metamorphosis. J. Insect Physiol. 59, 1089-1094. doi: 10.1016/j.jinsphys.2013. 09.003

Sawata, M., Yoshino, D., Takeuchi, H., Kamikouchi, A., Ohashi, K., and Kubo, T. (2002). Identification and punctate nuclear localization of a novel noncoding RNA, Ks-1, from the honeybee brain. RNA 8, 772-785. doi: $10.1017 /$ S 1355838202028790

Schmieder, R., and Edwards, R. (2011). Quality control and preprocessing of metagenomic datasets. Bioinformatics 27, 863-864. doi: 10.1093/bioinformatics/btr026

Schwander, T., Humbert, J.-Y., Brent, C. S., Cahan, S. H., Chapuis, L., Renai, E., et al. (2008). Maternal effect on female caste determination in a social insect. Curr. Biol. 18, 265-269. doi: 10.1016/j.cub.2008.01.024

Soares, M. P. M., Barchuk, A. R., Quirino Simões, A. C., Cristino, A. S., Freitas, F. C. P., Canhos, L. L., et al. (2013). Genes involved in thoracic exoskeleton formation during the pupal-to-adult molt in a social insect model, Apis mellifera. BMC Genomics 14:576. doi: 10.1186/1471-2164-14-576

Soares, M. P. M., Elias-Neto, M., Simões, Z. L. P., and Bitondi, M. M. G. (2007). A cuticle protein gene in the honeybee: Expression during development and in relation to the ecdysteroid titer. Insect Biochem. Mol. Biol. 37, 1272-1282. doi: 10.1016/j.ibmb.2007.07.014

Soares, M. P. M., Silva-Torres, F. A., Elias-Neto, M., Nunes, F. M. F., Simões, Z. L. P., and Bitondi, M. M. G. (2011). Ecdysteroid-dependent expression of the Tweedle and Peroxidase genes during adult cuticle formation in the honey bee, Apis mellifera. PLoS ONE 6:e20513. doi: 10.1371/journal.pone. 0020513

Sokol, N. S., and Ambros, V. (2005). Mesodermally expressed Drosophila microRNA-1 is regulated by Twist and is required in muscles during larval growth. Genes Dev. 19, 2343-2354. doi: 10.1101/gad.1356105

Sokol, N. S., Xu, P., Jan, Y. N., and Ambros, V. (2008). Drosophila let-7 microRNA is required for remodeling of the neuromusculature during metamorphosis. Genes Dev. 22, 1591-1596. doi: 10.1101/gad.1671708

Sultan, A.-R. S., Oish, Y., and Ueda, H. (2014). Function of the nuclear receptor FTZ-F1 during the pupal stage in Drosophila melanogaster. Dev. Growth Diff. 56, 245-253. doi: 10.1111/dgd.12125

Takeuchi, H., Paul, R. K., Matsuzaka, E., and Kubo, T. (2007). EcR-A expression in the brain and ovary of the honeybee (Apis mellifera L.) Zool. Sci. 24, 596-603. doi: $10.2108 /$ zsj. 24.596

Talbot, W. S., Swyryd, E. A., and Hogness, D. S. (1993). Drosophila tissues with different metamorphic responses to ecdysone express different ecdysone receptor isoforms. Cell 73, 1323-1337. doi: 10.1016/0092-8674(93)90359-X

Tamura, S., Amano, S., Kono, T., Kondoh, J., Yamaguchi, K., Kobayashi, S., et al. (2009). Molecular characteristics and physiological functions of major royal jelly protein 1 oligomer. Proteomics 9, 5534-5543. doi: 10.1002/pmic. 200900541
The Honey Bee Genome Sequencing Consortium (2006). Insights into social insects from the genome of the honeybee Apis mellifera. Nature 443, 931-949. doi: $10.1038 /$ nature 05260

Tora, L., Gronemeyer, H., Turcotte, B., Gaub, M. P., and Chambon, P. (1988). The $\mathrm{N}$-terminal region of the chicken progesterone receptor specifies target gene activation. Nature 333, 185-188. doi: 10.1038/333185a0

Trapnell, C., Pachter, L., and Salzberg, S. L. (2009). TopHat: discovering splice junctions with RNA-Seq. Bioinformatics 25, 1105-1111. doi: 10.1093/bioinformatics/btp120

Trapnell, C., Williams, B. A., Pertea, G., Mortazavi, A., Kwan, G., van Baren, M. J., et al. (2010). Transcript assembly and quantification by RNA-Seq reveals unannotated transcripts and isoform switching during cell differentiation. Nat. Biotechnol. 28, 511-515. doi: 10.1038/nbt.1621

Varghese, J., and Cohen, S. M. (2007). microRNA miR-14 acts to modulate a positive autoregulatory loop controlling steroid hormone signaling in Drosophila. Genes Dev. 21, 2277-2282. doi: 10.1101/gad.439807

Velarde, R. A., Robinson, G. E., and Fahrbach, S. E. (2006). Nuclear receptors of the honey bee: annotation and expression in the adult brain. Insect Mol. Biol. 15, 583-595. doi: 10.1111/j.1365-2583.2006.00679.x

Velarde, R. A., Robinson, G. E., and Fahrbach, S. E. (2009). Coordinated responses to developmental hormones in the Kenyon cells of the adult worker honey bee brain (Apis mellifera L.). J. Insect Physiol. 55, 59-69. doi: 10.1016/j.jinsphys.2008.10.006

Watanabe, T., Takeuchi, H., and Kubo, T. (2010). Structural diversity and evolution of the N-terminal isoform-specific region of ecdysone receptor-A and -B1 isoforms in insects BMC Evol. Biol. 10:40. doi: 10.1186/1471-2148-10-40

Wienholds, E., and Plasterk, R. H. (2005). MicroRNA function in animal development. FEBS Lett. 579, 5911-5922. doi: 10.1016/j.febslet.2005.07.070

Yamanaka, N., Rewitz, K. F., and O'Connor, M. B. (2013). Ecdysone control of developmental transitions: lessons from Drosophila research. Annu. Rev. Entomol. 58, 497-516. doi: 10.1146/annurev-ento-120811-153608

Yang, M., Wei, Y., Jiang, F., Wang, Y., Guo, X., He, J., et al. (2014). MicroRNA-133 inhibits behavioral aggregation by controlling dopamine synthesis in locusts. PLoS Genet. 10:e1004206. doi: 10.1371/journal.pgen.1004206

Yao, T. P., Sagraves, W. A., McKeown, M., and Evans, R. M. (1992). Drosophila ultraspiracle modulates ecdysone receptor function via heterodimer formation. Cell 71, 63-72. doi: 10.1016/0092-8674(92)90266-F

Zitnan, D., and Adams, M. E. (2012). "Neuroendocrine regulation of ecdysis," in Insect Endocrinology, ed L. I. Gilbert (San Diego, CA: Academic Press), 253-309.

Conflict of Interest Statement: The authors declare that the research was conducted in the absence of any commercial or financial relationships that could be construed as a potential conflict of interest.

Received: 28 September 2014; accepted: 04 December 2014; published online: 22 December 2014.

Citation: Mello TRP, Aleixo AC, Pinheiro DG, Nunes FMF, Bitondi MMG Hartfelder K, Barchuk AR and Simões ZLP (2014) Developmental regulation of ecdysone receptor $(E c R)$ and EcR-controlled gene expression during pharate-adult development of honeybees (Apis mellifera). Front. Genet. 5:445. doi: 10.3389/fgene. 2014.00445

This article was submitted to Evolutionary and Population Genetics, a section of the journal Frontiers in Genetics.

Copyright (c) 2014 Mello, Aleixo, Pinheiro, Nunes, Bitondi, Hartfelder, Barchuk and Simóes. This is an open-access article distributed under the terms of the Creative Commons Attribution License (CC BY). The use, distribution or reproduction in other forums is permitted, provided the original author(s) or licensor are credited and that the original publication in this journal is cited, in accordance with accepted academic practice. No use, distribution or reproduction is permitted which does not comply with these terms. 